Thais Flügel Mathias Paschoal

\author{
Manual Cirúrgico de Periodontia: Técnicas \\ cirúrgicas para terapia da bolsa periodontal e \\ cirurgia de aumento de coroa clínica com \\ finalidade restauradora
}

Brasília

2018 

Thais Flügel Mathias Paschoal

\section{Manual Cirúrgico de Periodontia: Técnicas cirúrgicas para terapia da bolsa periodontal e cirurgia de aumento de coroa clínica com finalidade restauradora}

Trabalho de Conclusão de Curso apresentado ao Departamento de Odontologia da Faculdade de Ciências da Saúde da Universidade de Brasília, como requisito parcial para a conclusão do curso de Graduação em Odontologia.

Orientadora: Prof. Dra. Valéria Martins de Araújo Carneiro

Coorientadora: Prof. Dra. Maria do Carmo Machado Guimarães

Brasília 

Dedico este trabalho à minha família, a Deus e às minhas professoras. 



\section{AGRADECIMENTOS}

À minha mãe, Emmily, e meu pai, Wagner, pela paciência e toda a força durante essa jornada.

À toda a minha família, pelo acolhimento e palavras de incentivo.

Ao Vítor, meu namorado, pela ajuda e motivação.

À minha dupla, Letícia, por todo o companheirismo e risadas durante $o$ curso.

Aos meus amigos, Mayla, Nathália, Carol, Rafael e Raul, por todos os momentos de descontração e carinho.

À turma 67, por terem participado comigo deste momento tão especial da minha vida.

À minha orientadora, Professora Valéria, por todo a dedicação e ensinamentos.

À minha coorientadora, Professora Maria do Carmo, por toda a colaboração e suporte. 

"Entre o objetivo e a meta, faz-se imperativo o esforço constante e inadiável."

Chico Xavier 

PASCHOAL, Thais F M. Manual Cirúrgico de Periodontia: Técnicas cirúrgicas para terapia da bolsa periodontal e cirurgia de aumento de coroa clínica com finalidade restauradora. 2018. Trabalho de Conclusão de Curso (Graduação em Odontologia) Departamento de Odontologia da Faculdade de Ciências da Saúde da Universidade de Brasília.

As cirurgias para o tratamento da doença periodontal surgiram antes que se compreendessem os mecanismos de ação da placa bacteriana. O reconhecimento de que a redução da carga bacteriana impacta na regressão do processo inflamatório foi essencial para que as cirurgias de acesso para raspagem sofressem mudanças, tornando os procedimentos cirúrgicos atuais mais conservadores. O presente estudo se propõe a apresentar um resumo progressivo das abordagens cirúrgicas para terapia da bolsa periodontal, assim como da cirurgia de aumento de coroa clínica com finalidade restauradora. $\mathrm{Na}$ literatura dos procedimentos cirúrgicos periodontais, há uma variedade de técnicas, cujas nomenclaturas e conceitos diferem entre os diversos autores. Dessa forma, este trabalho reúne os procedimentos cirúrgicos mais utilizados na Periodontia, apresentados por meio de textos e esquemas ilustrativos. Além disso, traz um olhar do passado, com o histórico evolutivo das técnicas e pensamentos relacionados ao tema. 

PASCHOAL, Thais F M. Periodontal Surgical Guide: Surgical techniques for periodontal pocket therapy and restorative crown surgery. 2018. Undergraduate Course Final Monograph (Undergraduate Course in Dentistry) - Department of Dentistry, School of Health Sciences, University of Brasília.

Surgeries for the treatment of periodontal diseases arose prior to the knowledge and understanding of the mechanism of action of the bacterial plaque. With a better understanding of the importance of reducing bacterial load to reduce the inflammatory process, periodontal access surgeries have undergone progressive changes and current surgical procedures are considered more conservative. The present study aims to summarize the past and current literature regarding surgical approaches to periodontal pocket therapy, as well as the focus on restorative crown surgery. Regarding periodontal surgical procedures, in the literature, there is a variety of techniques, whose nomenclatures and concepts differ between the different authors. Thus, this literature review brings together the surgical procedures most used in periodontics, presenting them through illustrative texts and schemas, to further elucidate the topic. In addition, this paper brings back a look from the past, with the evolutionary history of the techniques and thoughts about the theme. 

$\begin{array}{ll}\text { Resumo } & 22\end{array}$

$\begin{array}{ll}\text { Abstract } & 24\end{array}$

Introdução 25

Revisão de Literatura $\quad 27$

$\begin{array}{ll}\text { Cirurgia Periodontal } & 27\end{array}$

Objetivos das Cirurgias Periodontais $\quad 28$

Terapia Cirúrgica para Tratamento da Bolsa 29

Gengivectomia $\quad 29$

Cirurgias a Retalho para Tratamento da Bolsa $\quad 30$

Retalho de Widman $\quad 30$

Retalho de Neumann 31

Retalho de Kirkland $\quad 32$

Retalho de Widman Modificado $\quad 33$

Deslocamento Apical do Retalho $\quad 34$

ENAP e ENAP Modificado $\quad 36$

Terapia Atual para Tratamento da Bolsa 37

Retalho de Kirkland $\quad 37$

Técnica Cirúrgica $\quad 38$

Gengivectomia Interna $\quad 39$

Técnica Cirúrgica $\quad 40$

Cunha Distal $\quad 41$

Técnica Cirúrgica $\quad 42$

Cunha Interproximal $\quad 43$

Técnica Cirúrgica $\quad 44$

Cirurgias com Finalidade Restauradora $\quad 45$ 
Cirurgia de Aumento de Coroa Clínica com Finalidade Restauradora

Indicações para Cirurgia de ACC com Finalidade Restauradora

Contra-Indicações

Diferentes Retalhos Utilizados na Cirurgia de ACC com Finalidade Restauradora

Retalhos de Espessura Total Indicações

Retalhos de Espessura Parcial Indicações

Retalhos Mistos

Técnicas Cirúrgicas para ACC com Finalidade Restauradora

Gengivectomia de Bisel Externo

Gengivoplastia

Indicações atuais para

Gengivectomia/Gengivoplastia

Condições para a Execução da Técnica $\quad 60$

Contra-Indicações

60

Técnica Cirúrgica

60

Retalhos Palatinos

56

Retalhos Vestibulares

Osteotomia

65

Osteoplastia

65

Técnica Cirúrgica da Osteotomia/Osteoplastia $\quad 66$

Cura da Ferida Cirúrgica após Terapia Periodontal

Cura da Ferida Cirúrgica Pós-Gengivectomia/Gengivoplastia

Cura Pós-Cirurgia a Retalho

Sutura Proximal de Laço Simples

Sutura em Oito 
Sutura Colchoeiro Horizontal

Sutura Colchoeiro Vertical

Instrumentais Cirúrgicos

Cinzéis

Curetas

Gengivótomos

Brocas

Outros Instrumentais

Metodologia

Conclusão

Error! Bookmark not defined.

Referências Bibliográficas

82

Anexos

88

Normas da Revista 



\section{ARTIGO CIENTÍFICO}

Este trabalho de Conclusão de Curso é baseado no artigo científico:

PASCHOAL, Thais F M; GUIMARÃES, Maria do Carmo M; CARNEIRO, Valéria $M$ de A. Manual Cirúrgico de Periodontia: Técnicas cirúrgicas para tratamento da bolsa periodontal e cirurgia de aumento de coroa clínica com finalidade restauradora.

Apresentado sob as normas de publicação da Revista SOBRAPE 


\section{FOLHA DE TÍTULO}

Manual Cirúrgico de Periodontia: Técnicas cirúrgicas para terapia da bolsa periodontal e cirurgia de aumento de coroa clínica com finalidade restauradora

Periodontal Surgical Guide: Surgical techniques for periodontal pocket therapy and restorative crown surgery

Thais F M Paschoal ${ }^{1}$

Maria do Carmo M Guimarães ${ }^{2}$

Valéria $\mathrm{M}$ de $\mathrm{A}$ Carneiro ${ }^{3}$

1 Aluna de Graduação em Odontologia da Universidade de Brasília.

${ }^{2}$ Professora Adjunta de Periodontia da Universidade de Brasília (UnB).

${ }^{3}$ Professora Adjunta de Periodontia da Universidade de Brasília (UnB).

Correspondência: Prof. Dra. Valéria Martins de Araújo Carneiro Campus Universitário Darcy Ribeiro - UnB - Faculdade de Ciências da Saúde - Departamento de Odontologia - 70910-900 Asa Norte - Brasília - DF

E-mail: valeriamartinsc@gmail.com / Telefone: (61) 31071849 


\section{RESUMO}

Manual Cirúrgico de Periodontia: Técnicas cirúrgicas para terapia da bolsa periodontal e cirurgia de aumento de coroa clínica com finalidade restauradora

As cirurgias para o tratamento da doença periodontal surgiram antes que se compreendessem os mecanismos de ação da placa bacteriana. O reconhecimento de que a redução da carga bacteriana impacta na regressão do processo inflamatório foi essencial para que as cirurgias de acesso para raspagem sofressem mudanças, tornando os procedimentos cirúrgicos atuais mais conservadores. O presente estudo se propõe a apresentar um resumo progressivo das abordagens cirúrgicas para terapia da bolsa periodontal, assim como da cirurgia de aumento de coroa clínica com finalidade restauradora. $\mathrm{Na}$ literatura dos procedimentos cirúrgicos periodontais, há uma variedade de técnicas, cujas nomenclaturas e conceitos diferem entre os diversos autores. Dessa forma, este trabalho reúne os procedimentos cirúrgicos mais utilizados na Periodontia, apresentados por meio de textos e esquemas ilustrativos. Além disso, traz um olhar do passado, com o histórico evolutivo das técnicas e pensamentos relacionados ao tema.

\section{Palavras-chave}

Cirurgia periodontal; Tratamento periodontal; Cirurgias ressectivas; Cirurgia a retalho

\section{Relevância Clínica}

A necessidade da realização de cirurgias periodontais no cotidiano clínico é muito frequente e, por isso, é um assunto que 
deve ser bem esclarecido para alunos de graduação e profissionais da Odontologia. 


\section{ABSTRACT}

Periodontal Surgical Guide: Surgical techniques for periodontal pocket therapy and restorative crown surgery

Surgeries for the treatment of periodontal diseases arose prior to the knowledge and understanding of the mechanism of action of the bacterial plaque. With a better understanding of the importance of reducing bacterial load to reduce the inflammatory process, periodontal access surgeries have undergone progressive changes and current surgical procedures are considered more conservative. The present study aims to summarize the past and current literature regarding surgical approaches to periodontal pocket therapy, as well as the focus on restorative crown surgery. Regarding periodontal surgical procedures, in the literature, there is a variety of techniques, whose nomenclatures and concepts differ between the different authors. Thus, this literature review brings together the surgical procedures most used in periodontics, presenting them through illustrative texts and schemas, to further elucidate the topic. In addition, this paper brings back a look from the past, with the evolutionary history of the techniques and thoughts about the theme.

\section{Keywords}

Periodontal surgery; Periodontal treatment; Resective procedures; Flap surgery 


\section{INTRODUÇÃO}

As doenças bucais têm sido estudadas e documentadas desde os primórdios da humanidade. Vários estudiosos pelo mundo pesquisaram e escreveram a respeito, incluindo seus tratamentos e modo de prevenção. (Carranza et al., 2016)

Acreditava-se, até o final do século XIX, que o cálculo dental era responsável pela doença periodontal (Duarte, 2009). Em 1883, Miller iniciou um estudo sobre a correlação da presença de microrganismos na superfície dentária com a produção de ácidos, que iniciavam a desmineralização dos dentes. A teoria foi intitulada "Teoria Químico-Parasitária da Cárie Dentária". (Miller, 1890)

Em 1895, Black voltou a mencionar o estudo de Miller, acrescentando que as doenças que envolvem a cavidade bucal podem estar associadas também às condições de higiene bucal e fluxo salivar de cada indivíduo. (Black, 1895)

A partir de 1902, o termo "placa bacteriana", imposto também por Miller, foi se tornando comum dentro da Odontologia, possibilitando o aprofundamento dos estudos a respeito dos microrganismos e suas relações com as doenças bucais (Miller, 1890).

O trabalho de gengivite experimental em humanos, desenvolvido por Löe et al., (1965), marcou a importância das bactérias nas doenças periodontais. O referido estudo evidenciou inflamação gengival em todos os voluntários, cerca de dez a vinte e um dias após deixarem a placa bacteriana acumular-se sobre seus dentes. Além disso, o experimento demonstrou que o retorno da higienização por parte dos voluntários fez com que a microbiota original fosse reinstalada, assim como houve o restabelecimento da saúde gengival.

Entretanto, de acordo com o modelo de Page e Kornman, (1997), observou-se que o grau e gravidade da manifestação clínica das periodontites dependem da forma como os componentes da 
susceptibilidade do hospedeiro, especialmente resposta imunoinflamatória, são modulados pelos fatores ambientais e de risco adquiridos, além dos genéticos. A despeito deste conhecimento, a terapia mecânica no tratamento da DP, incluindo o tratamento cirúrgico, seja para tratar a doença ou devolver a fisiologia dento-gengival, são importantes.

Dessa forma, aperfeiçoaram-se os procedimentos e técnicas cirúrgicas periodontais, com intuito de se conseguir melhor alcance do biofilme pelo profissional e, consequentemente, melhor resposta do hospedeiro.

Cabe ressaltar o valor primordial da desorganização do biofilme no tratamento das doenças periodontais, por meio da terapia periodontal básica e higiene bucal. $\mathrm{Na}$ terapia periodontal básica, a instrumentação não cirúrgica tem como objetivo a remoção do cálculo supra e subgengival, proporcionando uma superfície radicular lisa com preservação do cemento não contaminado. Dessa forma, é capaz de modificar o meio, resultando na redução de peridontopatógenos e no restabelecimento de uma microbiota não patogênica compatível com a saúde periodontal. (Petersilka et al., 2002)

Não obstante o papel da terapia periodontal não cirúrgica, há situações em que há indicação de técnicas cirúrgicas para raspagem a campo aberto, além de técnicas ressectivas e regenerativas. (Kalkwarf, 1989).

Assim, o objetivo do estudo é discorrer a respeito dos diferentes procedimentos cirúrgicos que visam não apenas ao tratamento das doenças periodontais, mas também à devolução da fisiologia na área dento-gengival visando, sobretudo, à devolução das distâncias biológicas perdidas ou invadidas. 


\section{METODOLOGIA}

A metodologia adotada para a realização do presente trabalho constituiu-se em uma revisão bibliográfica a respeito do tema: Cirurgia Periodontal. Com isso, foram selecionados artigos científicos e livros-texto publicados no período de 1890 a 2017. O critério usado na seleção dos artigos baseou-se nas referências apontadas pelos livros clássicos utilizados pela Periodontia. Foram empregados o total de 38 artigos e quinze livros, com o objetivo de identificar aspectos relevantes acerca da evolução das técnicas cirúrgicas periodontais.

Os desenhos foram realizados pelo programa CorelDRAW 2017, por meio de vetorização de imagens, para facilitar a compreensão dos diferentes conceitos, técnicas cirúrgicas e outros elementos necessários para o entendimento da temática abordada. Algumas figuras foram adaptadas de imagens preexistentes, enquanto outras foram criadas a partir dos conceitos e técnicas estudados.

\section{REVISÃO DE LITERATURA}

\section{CIRURGIA PERIODONTAL}

Com o decorrer dos anos e com a evolução dos estudos acerca da biologia do periodonto e melhor compreensão do processo de cura, passou a se questionar a eliminação da bolsa periodontal, anteriormente considerada o principal objetivo da cirurgia periodontal no tratamento da doença periodontal. (Lindhe et al., 2011)

A placa bacteriana é considerada o fator primário da maioria das doenças periodontais. Sendo assim, as cirurgias periodontais têm como objetivo facilitar a remoção de depósitos subgengivais, 
além de contribuir para uma melhor higiene bucal. Ou seja, coopera, a longo prazo, para uma manutenção da saúde periodontal. Tais benefícios contribuem no restabelecimento de um periodonto saudável. (Lindhe et al. 2011)

O correto prognóstico e avaliação do paciente para realização da cirurgia periodontal depende da redução da inflamação e dos depósitos de cálculo e placa bacteriana, por meio da raspagem e alisamento radicular (Lindhe et al. 2011). Ou seja, as cirurgias periodontais somente poderão ser realizadas após preparo básico inicial e bom alcance quanto ao controle de placa pelo paciente (Goldman, 1946).

OBJETIVOS DAS CIRURGIAS PERIODONTAIS (Duarte, 2009):

- Facilitar acesso para raspagem e alisamento radicular;

- Eliminar ou reduzir bolsas periodontais;

- Obter condições anatômicas que facilitem a higienização bucal;

- Aumentar coroa clínica e/ou restabelecer o espaço biológico;

- Regenerar tecidos periodontais perdidos.

Alguns livros classificam as técnicas cirúrgicas de acordo com os tecidos periodontais envolvidos. Dessa forma, a gengivectomia e a gengivoplastia estão relacionadas apenas às mucosas marginal livre, papilar e ceratinizada, sem atingir outras estruturas. No entanto, quando há necessidade de intervenção no tecido ósseo, seja para tratamentos ressectivos ou regenerativos (exemplos: uso de enxerto ou de membrana) utilizam-se os retalhos totais. Por fim, para manipulação restrita à mucosa alveolar e gengival, visando à sua preservação, os retalhos divididos são empregados. (Schluger et al., 1977; Ramfjord \& Ash, 1979; Genco et al., 1997; Lindhe et al., 2011) 


\section{TERAPIA CIRÚRGICA PARA TRATAMENTO DA BOLSA}

Há alguns anos, alguns procedimentos cirúrgicos eram realizados para eliminação direta da bolsa periodontal que era classificada, de acordo com Glickman (Carranza, 1983), como um aprofundamento patológico do sulco gengival, acompanhado de destruição dos tecidos periodontais de suporte.

Para tanto, no decorrer do processo evolutivo dos princípios terapêuticos utilizados na Periodontia, são encontradas evidências na literatura de condutas cirúrgicas totalmente ressectivas, quando comparadas às técnicas hoje utilizadas. (Cardoso, \& Gonçalves, 2002) São algumas delas:

\section{GENGIVECTOMIA}

Em 1884, Robicsek iniciou o termo "Gengivectomia", que não tem a ver com a técnica hoje utilizada. Consistia em uma excisão do tecido gengival até a base da bolsa periodontal, por meio de uma incisão linear sobre cada dente, associada à remoção de osso marginal, pois acreditava-se que o processo alveolar adjacente à bolsa periodontal era um tecido necrótico (Stern, Everett, e Robicsek 1965).

Consequentemente, os dentes com a referida técnica apresentavam-se com aumento exagerado das coroas clínicas dentárias, prejudicando a estética. Desta forma, foi necessário o aprimoramento da técnica ao longo dos anos. (Saba-Chujfi, 2007)

Porém, em 1935, Rudolf Kronfeld demonstrou que o processo alveolar vizinho à parede da bolsa periodontal não apresentava características de um tecido necrosado, não sendo necessária a sua remoção. (Cardoso \& Gonçalves, 2002)

Atualmente, a gengivectomia é uma técnica utilizada em casos específicos, em que não é necessária a remodelação óssea, e 
sim um recontorno gengival para corrigir crescimento gengival e realizar aumento de coroa clínica com finalidade estética e restauradora.

\section{CIRURGIAS A RETALHO PARA TRATAMENTO DA BOLSA}

Alguns procedimentos cirúrgicos a retalho também tiveram papel relevante no tratamento cirúrgico de bolsas periodontais. Acreditava-se que a eliminação total da bolsa era o único método eficaz de extinguir a doença periodontal (Cardoso \& Gonçalves, 2002). Considerando que em meados da década de sessenta a terapia de manutenção periodontal era pouco compreendida, os procedimentos cirúrgicos ressectivos foram muito empregados nessa época.

\section{RETALHO DE WIDMAN}

Essa técnica foi descrita em 1918 por Leonard Widman. Consistia na execução de um retalho total, por meio de duas incisões relaxantes, expondo de 2 a $3 \mathrm{~mm}$ da crista óssea. Além disso, realizava-se uma incisão a $1 \mathrm{~mm}$ da margem gengival (em bisel interno), para excisar um colar de tecido gengival "doente". (Lindhe et al., 2011)

O retalho de Widman tinha como objetivo eliminar bolsas periodontais, acessando as superfícies radiculares para facilitar a raspagem e remover tecido de granulação infectado, além de eliminar defeitos ósseos. (Cardoso \& Gonçalves, 2002) 

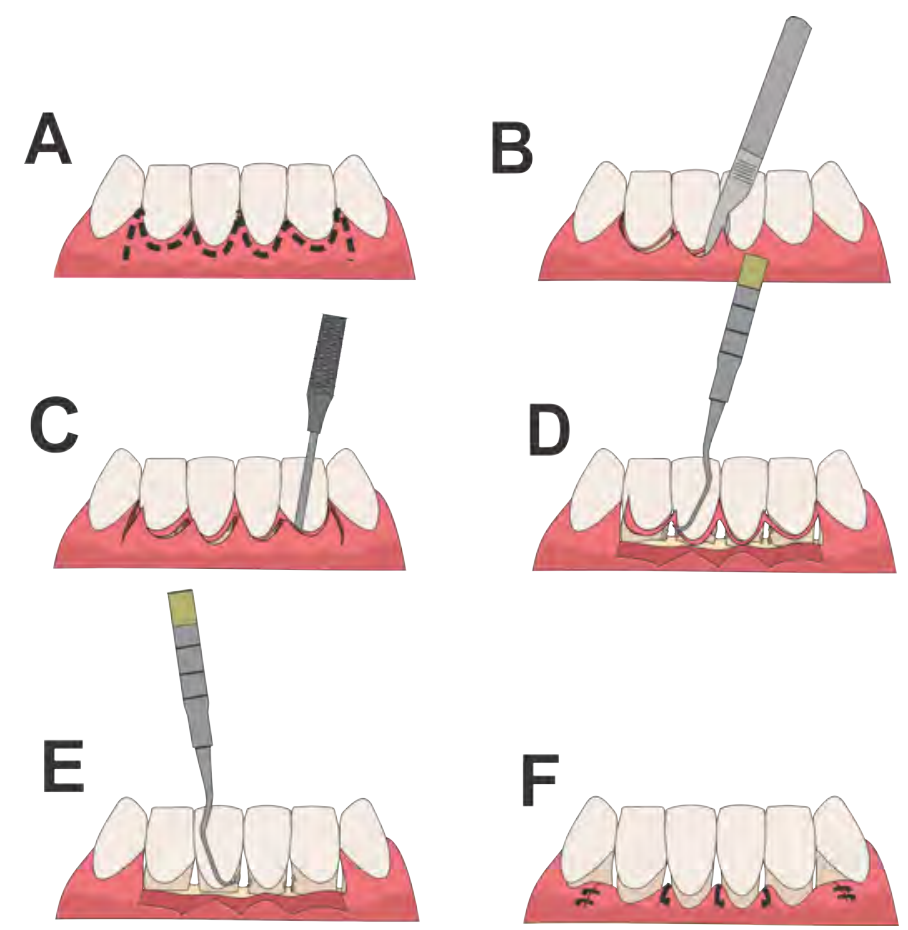

Figura 1: Retalho de Widman. Representação das incisões (A), incisões com bisel utilizando lâmina de bisturi $(B)$, descolamento do tecido com descolador de Molt (C), remoção do tecido biselado e dos tecidos de granulação com curetas Goldman Fox (D), raspagem e alisamento radicular $(E)$ e sutura $(F)$.

\section{RETALHO DE NEUMANN}

Robert Neumann, em 1920, elaborou e relatou uma técnica semelhante à de Widman, que consistia em executar incisões relaxantes para delimitar a área cirúrgica, além de incisão intrasulcular em torno dos dentes "doentes", em direção à base das bolsas periodontais. Com os tecidos devidamente divulsionados, a porção interna da gengiva e o osso eram 
curetados, com o intuito de remover tecido de granulação. Além disso, as superfícies radiculares eram raspadas e as irregularidades ósseas removidas. Por fim, o retalho era reposicionado apicalmente, na altura da crista óssea. (Lindhe et al., 2011)

A
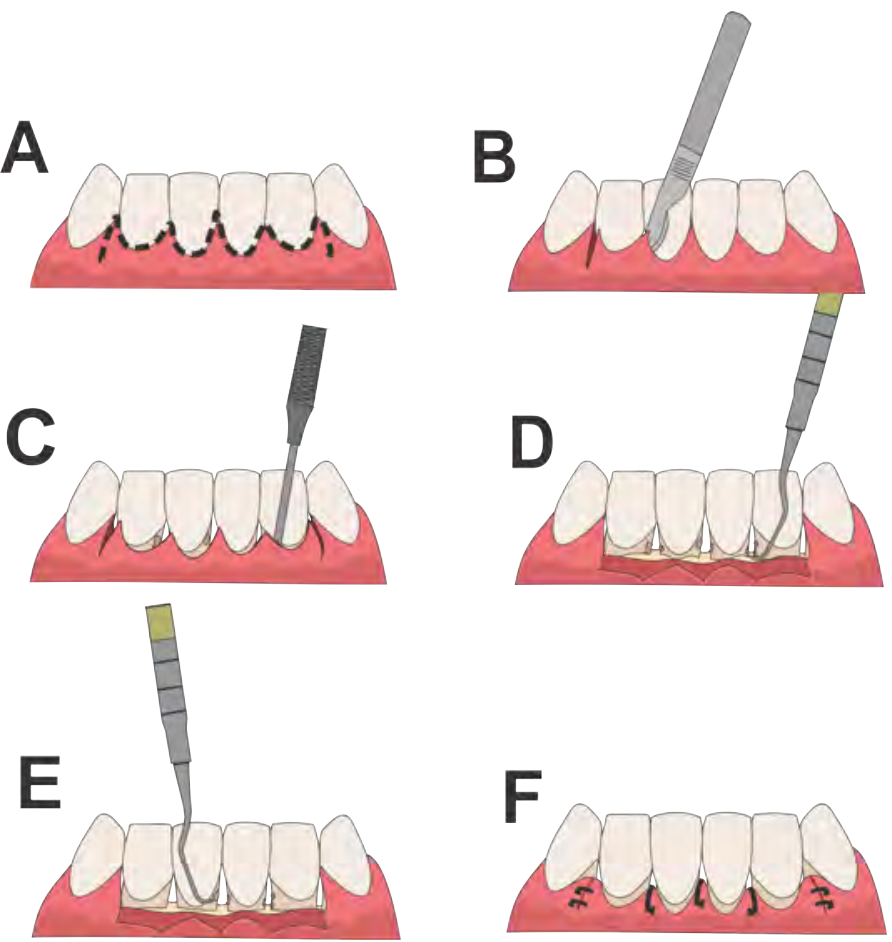

Figura 2: Retalho de Neumann. Representação das incisões (A), incisões relaxantes e intrasulculares (B), descolamento do tecido (C), curetagem dos tecidos de granulação (D), raspagem e alisamento radicular $(E)$ e resultado final $(F)$.

\section{RETALHO DE KIRKLAND}

Kirkland, em 1931, propôs uma técnica mais conservadora, que intitulou "Operação a Retalho Modificado". Esse procedimento 
deveria ser antecedido de remoção do cálculo dentário, polimento das superfícies dentárias e ajustes oclusais. (Cardoso \& Gonçalves, 2002)

Baseava-se no acesso às raízes dentárias por meio de incisões intrasulculares, que percorriam até a base das bolsas periodontais, tanto nas faces vestibular e palatina/lingual, quanto nas áreas interproximais. Depois, era feita a curetagem dos tecidos de granulação da face interna dos retalhos e eliminação do epitélio da bolsa, além da remoção de irregularidades no tecido ósseo. (Lindhe et al., 2011)

\section{RETALHO DE WIDMAN MODIFICADO}

Ramfjord e Nissle, em 1974, adaptaram a ideia de Widman e criaram uma técnica em que se realizava uma incisão biselada a 0,5 - $1 \mathrm{~mm}$ da margem gengival, paralela ao longo eixo do dente, descolando o retalho até a crista óssea (Lindhe et al., 2011). Com o retalho descolado, o bisel era removido e os defeitos ósseos curetados para remoção de tecido de granulação. Posteriormente, as superfícies dentárias eram raspadas e alisadas. A arquitetura óssea não era corrigida, exceto se impedisse uma boa adaptação tecidual. Suturas suspensórias contínuas independentes eram realizadas.

Essa técnica tinha como objetivo facilitar o acesso para raspagem que, consequentemente, acabava reduzindo a profundidade de sondagem. (Carranza et al., 2016) 

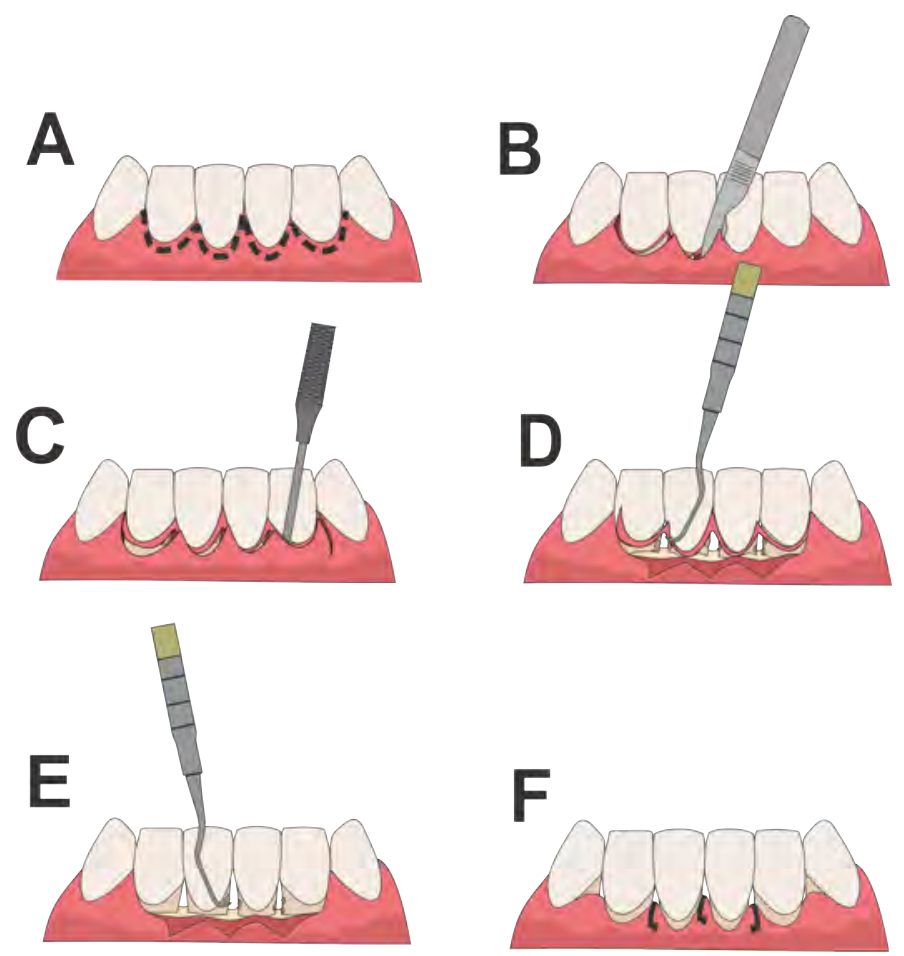

Figura 3: Retalho de Widman Modificado. Representação das incisões (A), incisões com bisel (B), descolamento do retalho com descolador de Molt (C), remoção do tecido biselado e curetagem dos tecidos de granulação com curetas Goldman Fox (D), raspagem e alisamento radicular $(E)$ e sutura $(F)$.

\section{DESLOCAMENTO APICAL DO RETALHO}

Nabers, (1954), ressaltou a importância da preservação da mucosa ceratinizada, observando que a diferença estrutural biológica entre esta e a mucosa alveolar poderia dificultar $o$ tratamento periodontal. Assim, desenvolveu uma técnica em que se fazia o deslocamento apical do retalho, reposicionando a mucosa ceratinizada em relação à crista óssea e preservando-a totalmente na incisão. 
Um retalho era realizado por meio de uma incisão relaxante na mesial referente à bolsa periodontal e, depois disso, o tecido de granulação era curetado. Então, o retalho era reposicionado apicalmente, cerca de $2 \mathrm{~mm}$ abaixo da posição original, onde era suturado. (Saba-Chujfi, 2007)

Em 1957, Ariaudo e Tyrrell propuseram uma modificação da técnica, com a realização de duas incisões relaxantes na mesial e distal da bolsa periodontal. A proposta era manter parte do osso coberto por periósteo, para que houvesse nova formação de mucosa ceratinizada. (Ariaudo \& Tyrrell, 1957)
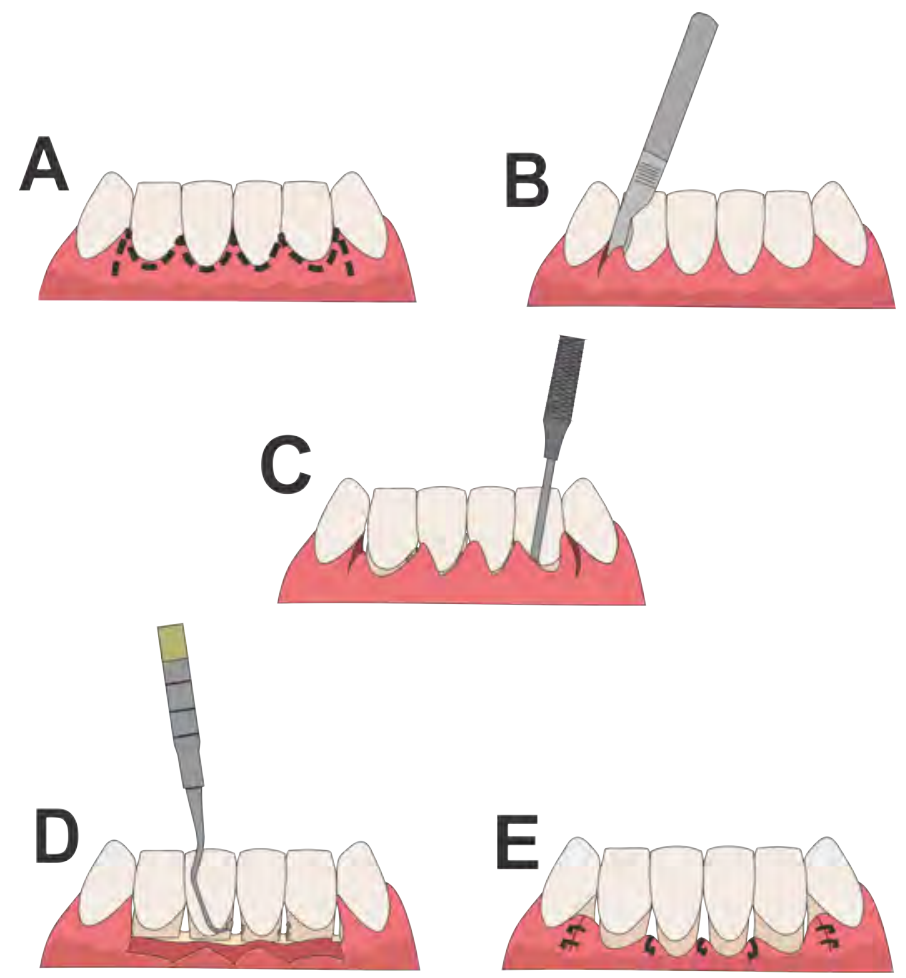

Figura 4: Deslocamento Apical do Retalho. Representação das incisões $(A)$, incisões relaxantes e intrasulculares na mesial das bolsas (B), descolamento do tecido com descolador de Molt (C), raspagem e alisamento radicular (D) e sutura (E). 

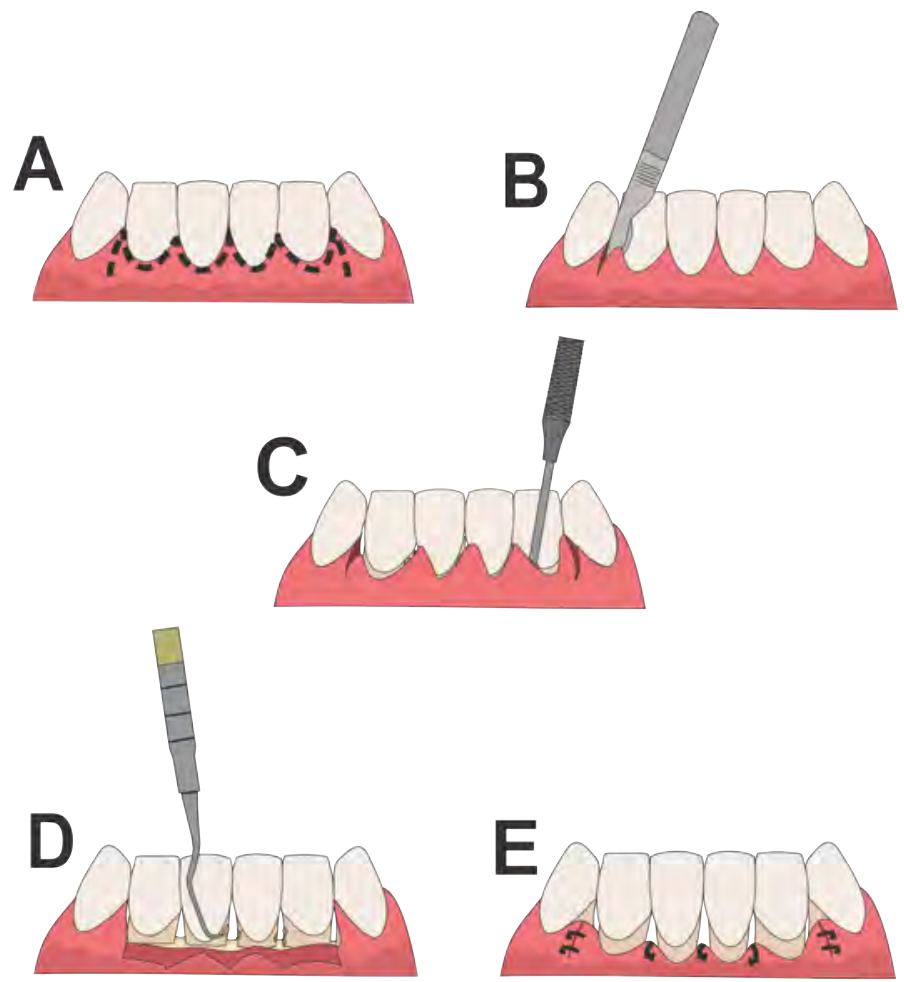

Figura 5: Deslocamento Apical do Retalho Modificado. Representação das incisões $(A)$, incisões relaxantes e intrasulculares na mesial e distal das bolsas (B), descolamento do tecido com descolador de Molt (C), raspagem e alisamento radicular $(D)$ e sutura $(E)$.

\section{ENAP E ENAP MODIFICADO}

O "Excisional New Attachment Procedure" (ENAP) foi criado por Yukna e colaboradores, em 1976. Esta técnica consistia em excisionar a parede interna da bolsa periodontal, por meio de uma incisão em direção à base da bolsa. Posteriormente, as superfícies radiculares eram raspadas. (Yukna, 1976)

Então, em 1977, foi proposto por Fedi e Rosenfeld uma pequena modificação do ENAP, para que a incisão terminasse na crista 
óssea, pela dificuldade de calcular onde se inseria a base da bolsa periodontal. (Fedi \& Rosenfeld, 1977)
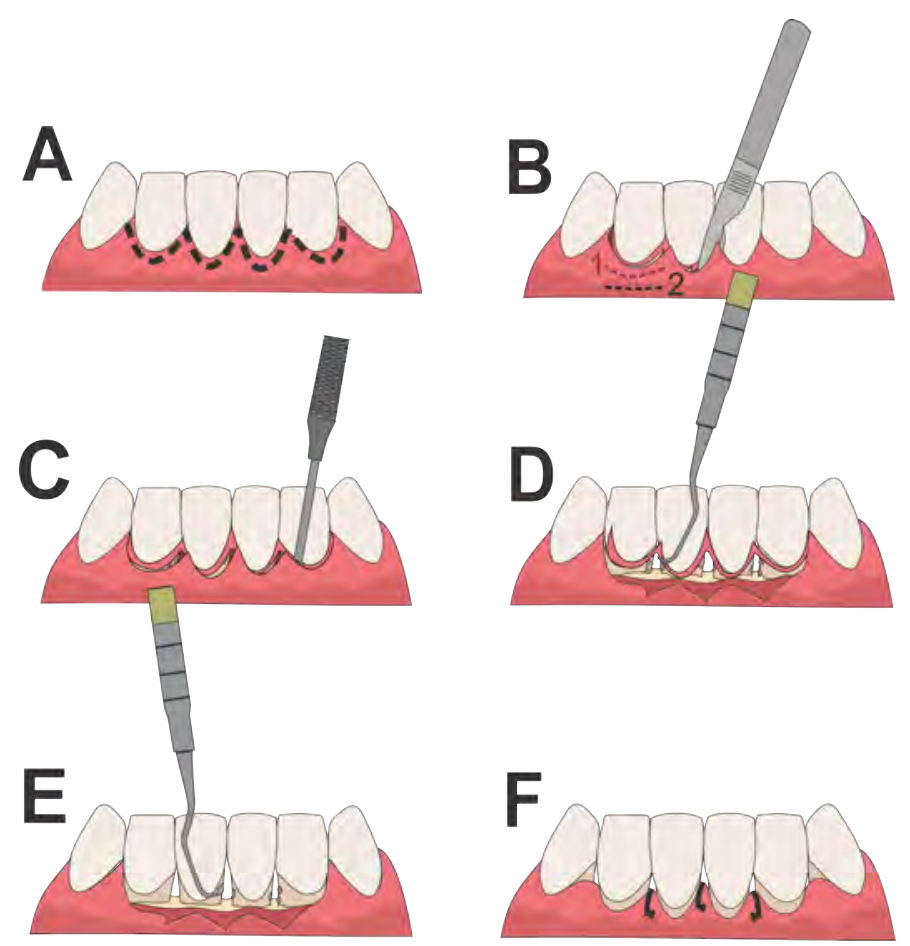

Figura 6: ENAP e ENAP Modificado. Representação das incisões (A), incisão em bisel até a base da bolsa (B.1 - ENAP) ou até a crista óssea (B.2 - ENAP Modificado), descolamento do retalho com descolador de Molt (C), remoção do tecido biselado e dos tecidos de granulação com curetas Goldman Fox (D), raspagem e alisamento radicular (E) e sutura $(\mathrm{F})$.

\section{TERAPIA ATUAL PARA TRATAMENTO DA BOLSA}

\section{RETALHO DE KIRKLAND}

Nos dias atuais, o retalho de Kirkland, citado anteriormente, é conhecido como "Retalho tipo Envelope". Este tipo de retalho é 
vantajoso por não expor demasiadamente as superfícies radiculares, causando trauma mínimo ao paciente e aos tecidos periodontais. (Lindhe et al., 2011)

Por ser um procedimento que visa ao acesso para raspagem, consequentemente acaba alterando a situação inflamatória dos tecidos periodontais, reduzindo ou eliminando a bolsa periodontal por meio de sondagem (Lindhe et al., 2011). Além disso, por não haver a necessidade de excisar tecido gengival, não altera significativamente a estética do sorriso e ameniza o pósoperatório. (Cardoso \& Gonçalves, 2002)

TÉCNICA CIRÚRGICA (Lindhe et al., 2011)

- Anestesiar a região;

- Realizar a incisão intrasulcular do sulco até a base da bolsa periodontal, ao redor dos dentes acometidos pela doença periodontal (Figura 7.B) e descolar o tecido, formando um retalho tipo "envelope" (Figura 7.C);

- Retirar os tecidos de granulação (Figura 7.D);

- Fazer o debridamento mecânico das superfícies radiculares expostas (Figura 7.E);

- Suturar com os retalhos em sua posição original (Figura 7.F). 

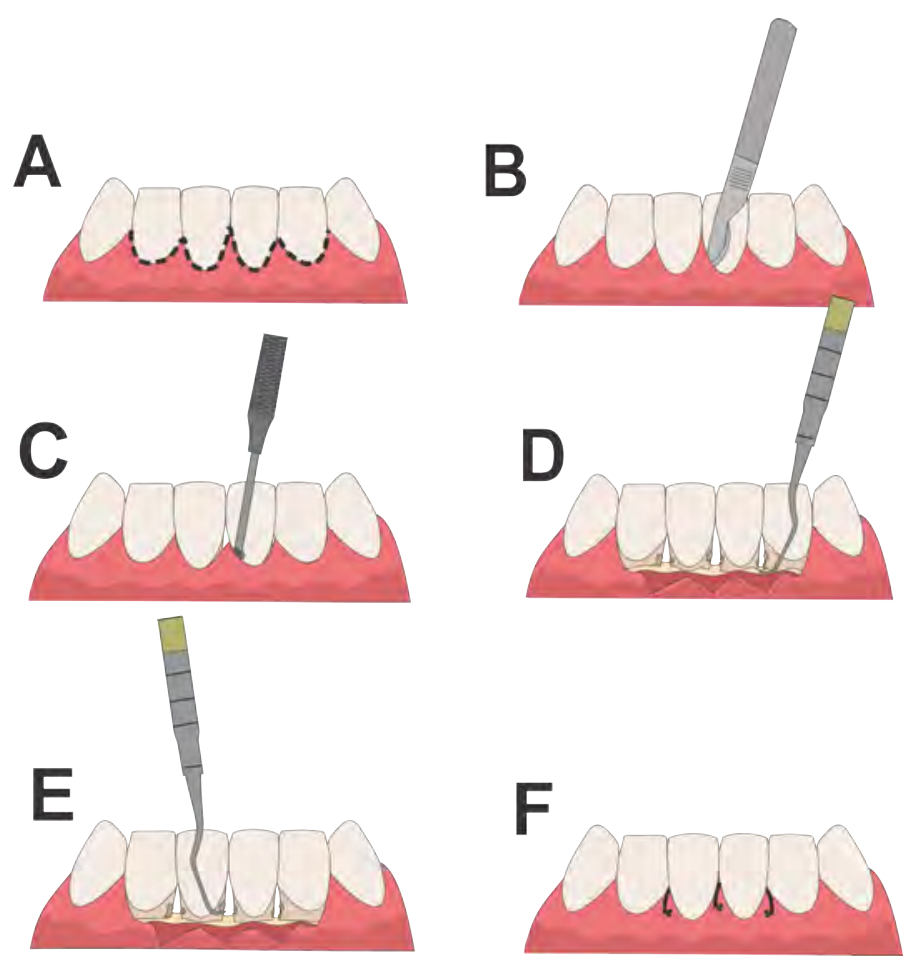

Figura 7: Retalho de Kirkland. Incisão intrasulcular (A e B), incisão intrasulcular (B), descolamento do tecido com descolador de Molt (C), curetagem do tecido de granulação (D), raspagem dos cálculos subgengivais $(E)$ e sutura $(F)$.

\section{GENGIVECTOMIA INTERNA}

Esse tipo de técnica é bem indicada para hiperplasias gengivais (medicamentosas e idiopáticas), que apresentem considerável espessura, uma vez que remove uma quantidade significativa de tecido fibrótico e a cura da ferida cirúrgica ocorre por primeira intenção, já que parte do tecido conjuntivo recoberto por epitélio é mantido (Duarte, 2009). Este procedimento é idealmente preconizado para redução de excesso de tecido mole na área 
palatina e para reduzir ou eliminar bolsa nessa área. (Staffileno et al., 1962)

Para realização da gengivectomia interna, são feitos três tipos de incisão: bisel interno, sulcular e horizontal, na base do tecido a ser excisado (Figura 2.C). Nessa técnica, o tecido gengival em excesso é reduzido internamente e o retalho é posicionado apicalmente. (Carranza et al., 2016)

Esta técnica permite criar margem gengival biselada, tendo como vantagem em relação à gengivectomia de bisel externo, a ocorrência de cura da ferida cirúrgica por primeira intenção (Carranza et al., 2016). Entretanto, na face vestibular, quando a espessura gengival não é acentuada e não há necessidade de remoção óssea, a técnica eleita é a gengivectomia de bisel externo, pela facilidade do procedimento e menor risco de dilaceração tecidual pela lâmina de bisturi.

\section{TÉCNICA CIRÚRGICA}

- Anestesiar a região;

- Sondagem da área, para verificar a profundidade de sondagem;

- Perfuração com sonda periodontal na distal do tecido, com referência na profundidade de sondagem, que irá guiar a primeira incisão (Figura 2.B);

- Realizar a incisão primária - bisel interno longo - a uma certa distância da margem gengival, terminando abaixo da crista óssea (a distância e profundidade dessa incisão depende da espessura tecidual e da quantidade de tecido a ser excisado) (Figura 8.C, número 1);

- Realizar a segunda incisão, intrasulcular, que corta as fibras gengivais dentro do sulco. É executada ao redor de todo o dente, até tocar a crista óssea (Figura 8.C, número 2); 
- Incisar o tecido em forma de cunha (integralidade da incisão primária e segunda incisão) em sua base, para excisionar este tecido (Figura 8.D);

- Curetar os tecidos de granulação (Figura 8. F);

- Suturar.
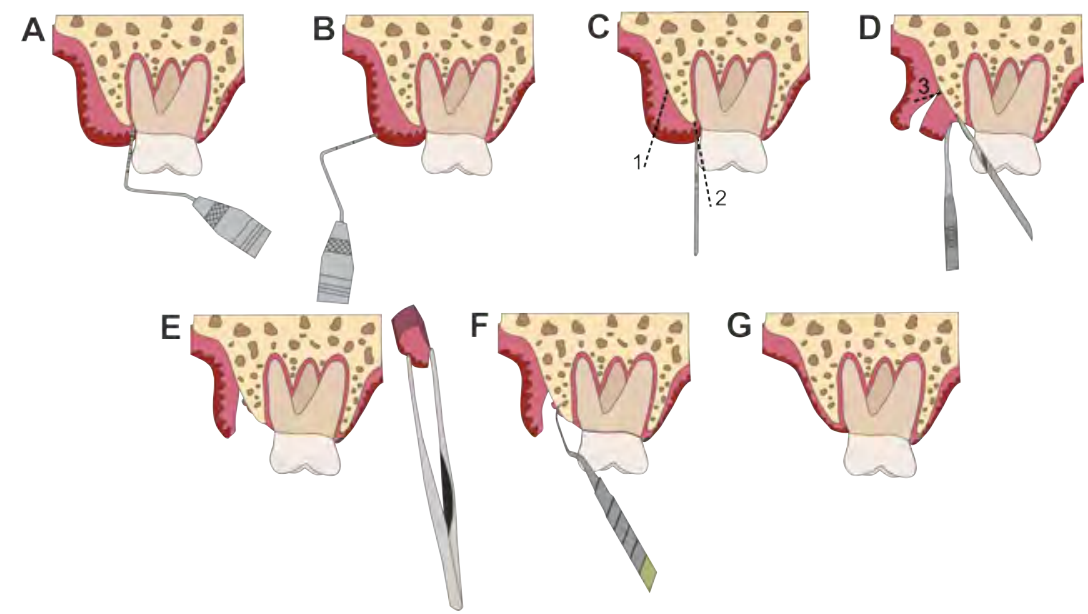

Figura 8: Gengivectomia Interna. Sondagem (A), representação das incisões (B), afastamento do tecido para realizar incisão horizontal (C), excisão (D), curetagem dos tecidos de granulação $(E)$ e resultado final $(\mathrm{F})$.

\section{CUNHA DISTAL}

Esta técnica foi descrita por Robinson, em 1966, e foi preconizada para eliminação ou redução de bolsas periodontais adjacentes às superfícies distais dos molares da maxila ou mandíbula. A inacessibilidade nas áreas com bolsa na tuberosidade maxilar ou espaço retromolar comprometem o controle biomecânico do biofilme pelo paciente, assim a técnica atende ao objetivo. (Robinson, 1966) 
A técnica de cunha distal utiliza incisões divergentes em direção ao tecido ósseo, com desenho triangular ou quadrangular (Figura 3.A, números 1 e 2, e Figura 3.B). (Robinson, 1966)

Além disso, é um procedimento que preserva uma quantidade suficiente de mucosa ceratinizada e alveolar, assegurando o recobrimento do osso com tecido mole para sutura (Lindhe et al., 2011).

Nas cirurgias de aumento de coroa clínica com finalidade protética, quando há invasão das distâncias biológicas nesta região, associado com volume tecidual, tanto em altura quanto em espessura, o acesso a esta área com o retalho tipo cunha é recomendado.

TÉCNICA CIRÚRGICA (Lindhe et al., 2011)

- Anestesiar a região;

- Realizar as incisões verticais nas faces vestibular e lingual/palatina, que se estendem desde a face distal do molar até próximo à tuberosidade ou trígono retromolar. (Lindhe et al., 2011) O formato da incisão é variável, em formato de triângulo ou retângulo, dependendo do formato da área (Cardoso \& Gonçalves, 2002). No túber da maxila, quando a cunha não está associada à gengivectomia interna, a largura das incisões nas faces vestibular e palatina não devem ultrapassar o ângulo diedro do dente. Isto é importante para que se consiga perfeita adaptação dos bordos vestibular e lingual do retalho (Figura 9.A e Figura 9.B);

- Descolar as paredes dos retalhos vestibular e lingual;

- Realizar a raspagem das superfícies radiculares e, se necessário, recontornar tecido ósseo;

- Reposicionar os retalhos vestibular e lingual sobre o osso. Se necessário, aparar o retalho com tesoura serrilhada 
Goldman Fox, ou afinar e aparar o retalho com lâmina de bisturi;

- Suturar em pontos simples ou contínuos (Figura 9.D).
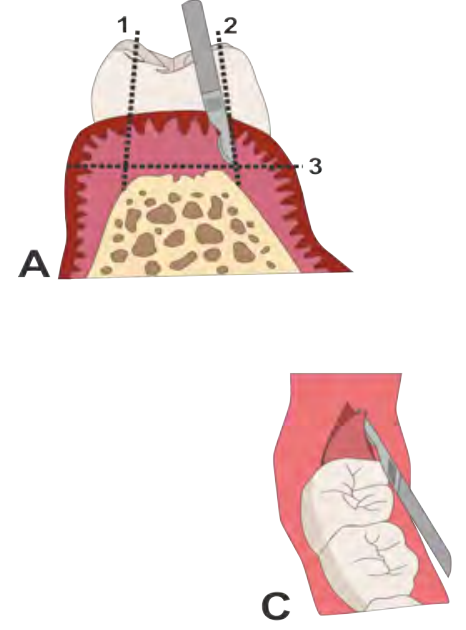

B

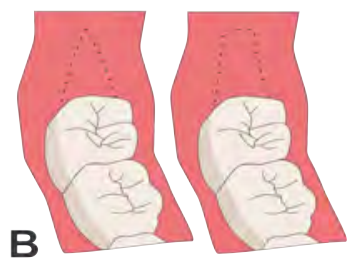

D

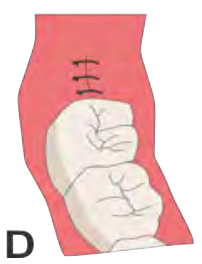

Figura 9: Cunha Distal. Representação das incisões (A) e dos formatos triangular ou retangular $(B)$, excisão do tecido $(C)$ e sutura $(D)$.

\section{CUNHA INTERPROXIMAL}

Esta técnica, também conhecida como "Paralela", é utilizada quando dentes adjacentes a um espaço protético têm presença de bolsa periodontal na mesial ou distal, seja verdadeira ou falsa (Duarte, 2009). O objetivo é preservar a mucosa ceratinizada naquela área e transformar a profundidade da bolsa em sulco gengival raso e, consequentemente, mais fisiológico. Dessa forma, possibilita-se uma higienização mais adequada por parte do paciente (Carranza et al., 2016).

Este tipo de retalho é preconizado em cirurgias de aumento de coroa clínica com finalidade protética, quando há invasão das 
distâncias biológicas nesta região, associado com volume tecidual, tanto em altura quanto em espessura.

TÉCNICA CIRÚRGICA (Duarte, 2009)

- Anestesiar a região;

- Realizar duas incisões divergentes no sentido da crista óssea (Figura 10.B);

- Realizar incisões verticais de bisel interno para contornar as faces mesial e distal dos dentes adjacentes ao espaço protético (Figura 10.B);

- Remover o tecido excisado e, se necessário, recontornar tecido ósseo (Figura 10.C);

- Suturar em pontos simples ou contínuos (Figura 10.D).
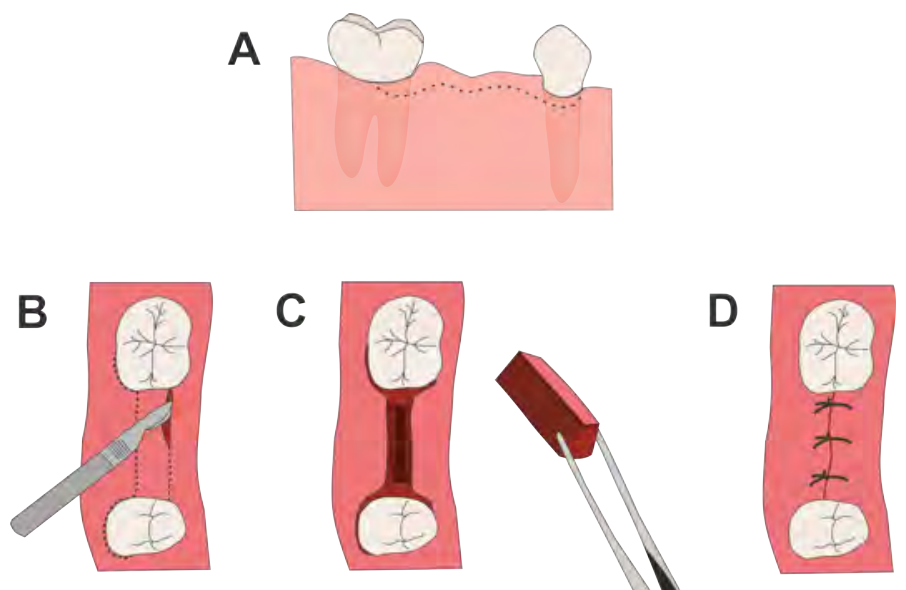

Figura 10: Cunha Interproximal. Representação do tecido a ser excisado (A), incisões verticais e divergentes (B), excisão do tecido (C) e sutura em pontos simples (D). 


\section{CIRURGIAS COM FINALIDADE RESTAURADORA}

\section{CIRURGIA DE AUMENTO DE COROA CLÍNICA COM FINALIDADE RESTAURADORA}

O espaço biológico (Figura 11) atua fisiologicamente como uma barreira protetora do osso alveolar e do ligamento periodontal e é atribuído à união biológica dos tecidos periodontais com a superfície dentária (Kina et al., 2011). Foi conceituado também como sendo a distância entre a base do sulco histológico até a crista óssea alveolar, que compreende a inserção conjuntiva e o epitélio juncional (Gargiulo et al., 1961).

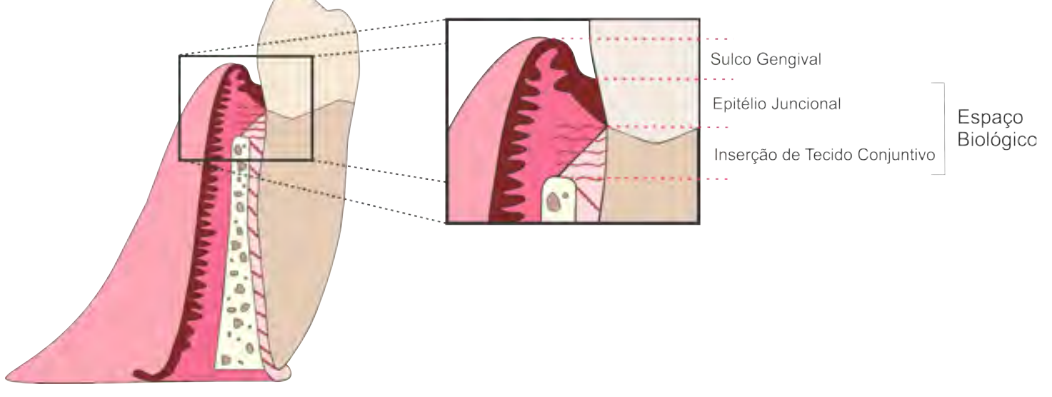

Figura 11: Espaço biológico e suas dimensões - sulco gengival, epitélio juncional e inserção de tecido conjuntivo.

Entretanto, Nevins e Skurow, (1984), definiram distância biológica como o espaço ocupado pelo sulco gengival, epitélio juncional e inserção conjuntiva. Independente da inclusão ou não da medida do sulco gengival como parte da medida da distância biológica, o mais importante é o conhecimento de que essas três estruturas integram o tecido gengival supra-ósseo ao redor dos dentes. Acredita-se que a formação do sulco gengival tenha ocorrido como forma de se evitar o contato direto do epitélio juncional, que é um tecido permeável, com a cavidade bucal, onde o número de agentes agressivos é considerável (Gonçalves \& Feller, 1998). 
O epitélio juncional é um tecido unido biologicamente ao dente, que forma o fundo do sulco gengival e é considerado uma estrutura de adaptação que, através de mecanismos homeostáticos, garante o equilíbrio fisiológico contra agressões possíveis do meio externo. (Schluger et al., 1977).

Já a área de inserção conjuntiva, conhecida também como "ligamento de Köllicker", é uma região onde as fibras do ligamento gengival se inserem no cemento supra-alveolar, desde o nível da crista óssea até a extremidade mais apical do epitélio juncional (Passanezi et al., 2011).

Quando o espaço biológico é invadido, um processo inflamatório pode ser provocado, fazendo com que o organismo estimule uma reabsorção do tecido ósseo periodontal, como uma tentativa de restabelecer a dimensão fisiológica das estruturas perdidas (Carvalho et. Al, 2016). Além disso, a violação do espaço biológico, seja por iatrogenia, trauma ou processos patológicos, pode causar inflamação gengival, formação de bolsa periodontal, e recessão gengival. (Baratieri et al., 2013)

Dessa forma, para o sucesso no tratamento restaurador, sem danos aos tecidos de sustentação, a cirurgia para o aumento de coroa clínica é indicada. Margens cavitárias localizadas subgengivalmente, que invadem o espaço biológico são frequentemente encontradas, sendo fundamental, dessa forma, a intervenção cirúrgica para devolução das condições de normalidade aos tecidos de sustentação. (Rissato \& Trentin, 2012)

O procedimento de aumento de coroa clínica (ACC) com finalidade restauradora surgiu como forma de permitir a realização de um preparo dentário adequado, facilitar procedimentos de moldagem e posicionamento de margens restauradoras (Kois \& Vakay, 2000).

É recomendada a manutenção de $3,0 \mathrm{~mm}$, em média, de estrutura dental sadia supra-alveolar para possibilitar que o epitélio juncional e a inserção conjuntiva se unam 
adequadamente ao dente remanescente (Herrero et al., 1995). Este número foi sugerido com base no estudo de Gargiulo et al., (1961), onde foram descritas as dimensões dentogengivais obtidas a partir de autopsias humanas. A média encontrada para as seguintes dimensões foi de $0,69 \mathrm{~mm}$ para o sulco gengival; $0,97 \mathrm{~mm}$ para epitélio juncional e $1,07 \mathrm{~mm}$ para a inserção conjuntiva, totalizando uma média de $2,73 \mathrm{~mm}$. No entanto, a literatura retrata medidas variáveis para o restabelecimento do espaço biológico, que podem variar de $3 \mathrm{~mm}$ a $5,25 \mathrm{~mm}$. (Nevins \& Skurow, 1984; Wagenberg et al., 1989)

É importante ressaltar que variações significativas na mensuração das dimensões foram encontradas, em particular no epitélio juncional, que variaram de 1,0 a 1,9 mm. Por outro lado, a inserção conjuntiva foi relativamente constante (Gargiulo et al., 1961). A variabilidade nas dimensões do espaço biológico se deve a fatores como: localização do dente no arco, face examinada, presença ou não de restaurações, tempo de cicatrização após cirurgia de aumento de coroa, doença periodontal, além de perda de inserção (Schmidt et al., 2013) e biotipo periodontal (Januário et al., 2008, Carvalho et al., 2016). Conforme abordado, a cirurgia de aumento de coroa tem como objetivo devolver ou preservar as distâncias biológicas, aumentando a coroa clínica do dente em questão. Assim, para um melhor entendimento deste conceito, classificam-se dois termos, conforme a Figura 12:

- Coroa Anatômica: Condiz com a estrutura dentária que vai da ponta da cúspide até a junção cemento-esmalte. (Ueti \& Matson, 1984)

- Coroa Clínica: Parte da estrutura dentária que é visível, que vai da margem gengival até a porção mais coronária do dente. (Cardoso \& Gonçalves, 2002) 


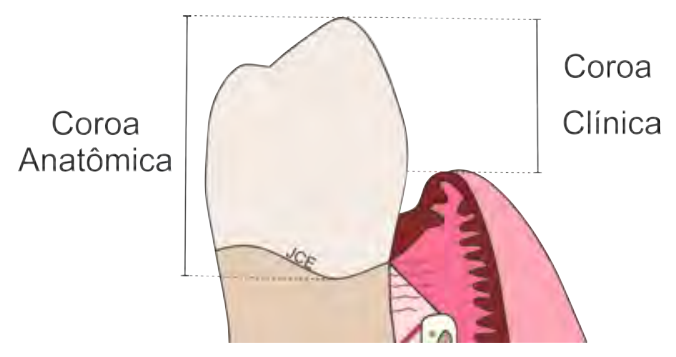

Figura 12: Representação das coroas anatômica e clínica.

Convencionalmente, pode-se considerar que há invasão do espaço biológico, quando o término cervical está localizado subgengivalmente, a uma distância menor ou igual a 2,0 mm da crista óssea.

Recomenda-se então, no aumento de coroa clínica, que haja no mínimo $3 \mathrm{~mm}$ entre a margem gengival e a crista óssea (Ingber et al., 1977), para possibilitar um posicionamento de uma restauração a $0,5 \mathrm{~mm}$ no interior do sulco gengival, distância essa compatível com a saúde periodontal, sem interferir no selamento biológico. (Baratieri et al., 2013) Porém, é importante salientar que, como cada paciente possui valores de espaço biológico diferentes, essas medidas são consideradas médias, o que faz com que o planejamento e indicação dos casos tenham que ser realizados cuidadosamente.

Para sua indicação e consequente tratamento reabilitador, o dente com indicação de ACC deve ser avaliado com cautela, observando os seguintes aspectos (Duarte, 2009):

- Extensão apical da cárie ou fratura em relação à crista óssea (através de sondagem periodontal e radiografia interproximal);

- Radiografia periapical para avaliar comprimento radicular, forma da raiz e, nas áreas interproximais, quantidade de invasão; 
- Profundidade de sondagem do dente em questão e dos adjacentes.

Além disso, é necessária a remoção de quaisquer causas de inflamação e infeç̧ão, como tecido cariado e resíduos de restaurações, tratamento endodôntico (quando indicado), remoção de cálculo dental, entre outros. (Fleming et al., 1991)

O aumento de coroa clínica pode incluir tanto a remoção de tecido mole, quanto de osso alveolar. A remoção apenas de tecido mole é indicada quando a distância do preparo à crista óssea encontra-se a uma distância maior que $3 \mathrm{~mm}$ e há quantidade suficiente de mucosa ceratinizada. Assim, a gengivectomia/gengivoplastia pode ser utilizada. (Carranza et al., 2016)

Entretanto, para casos em que há necessidade de recontorno ósseo para devolução das distâncias biológicas, recomenda-se as cirurgias à retalho (Brägger et al., 1992; Allen, 1993).

\section{INDICAÇÕES PARA CIRURGIA DE ACC COM FINALIDADE RESTAURADORA (Duarte, 2009; Carranza et al., 2016)}

- Cáries e fraturas subgengivais;

- Cáries, fraturas ou preparos dentais que invadam o espaço biológico;

- Coroas clínicas curtas que dificultam moldagem e retenção de restaurações;

- Perfurações subgengivais pós-tratamento endodôntico;

- Reabsorções radiculares. 
CONTRA-INDICAÇÕES (Duarte, 2009; Carranza et al., 2016)

- Impossibilidade de restaurar o dente;

- Comprometimento funcional ou estético do dente adjacente para manter 0 dente que necessita de intervenção;

- Importância do dente é menor do que a extensão de procedimentos necessários para salvá-lo;

- Relação coroa-raiz insatisfatória após ACC;

- Extensão da cárie ou fratura.

\section{RETALHOS UTILIZADOS NA CIRURGIA DE ACC COM FINALIDADE RESTAURADORA}

De acordo com Carranza et al., (2016), o retalho periodontal classifica-se como uma seç̧ão da gengiva e/ou mucosa cirurgicamente separada de seus tecidos subjacentes, para facilitar a visibilidade e o acesso ao tecido ósseo e à superfície radicular dos dentes.

Os retalhos podem ser não deslocados, quando o retalho é movimentado, mas é suturado na mesma posição, ou retalhos deslocados (apical, coronal ou lateral à sua posição original). Nesses casos, a mucosa ceratinizada deve ser totalmente separada do osso, seja pela técnica de retalho misto ou dividido, para que possibilite seu deslocamento. (Carranza et al., 2016) Por fim, os retalhos também podem ser divididos em retalhos de espessura total, parcial e mistos, sendo realizados na vestibular ou lingual/palatina dos dentes. (Carranza et al., 2016) 


\section{RETALHOS VESTIBULARES E LINGUAIS}

\section{RETALHO DE ESPESSURA TOTAL}

Também chamado de retalho mucoperiosteal, descola todo o tecido mole, inclusive o periósteo, para expor o osso subjacente (Sameera \& Harikumar, 2011).

Para áreas com quantidade considerável de mucosa ceratinizada, o retalho total é eleito. Quando a invasão das distâncias biológicas é na interproximal, uma incisão intrasulcular pode ser feita para realização do retalho total. Porém, quando a invasão é nas faces livres, realiza-se a técnica com bisel. Ressalta-se a importância de que a incisão com a lâmina de bisturi seja completa, para facilitar o deslocamento do retalho sem dilaceração tecidual.

\section{INDICAÇÕES}

São utilizados quando o objetivo é o acesso ao tecido ósseo para realização de osteotomia para restabelecimento da distância biológica ou para corrigir defeitos ósseos (Carranza et al., 2016). A incisão pode ser intrasulcular ou em bisel interno. Para a confecção de bisel interno é necessário que haja quantidade suficiente de mucosa ceratinizada.

\section{TÉCNICA CIRÚRGICA}

- Anestesiar a região;

- Sondagem do dente e de seus adjacentes;

- Iniciar a incisão - intrasulcular ou com bisel - (Figura 13.A e Figura 13.B); 
- Descolamento do tecido com descolador de Molt - iniciar pelas faces interproximais e seguir para as faces livres com movimentos de "meia-volta" (Figura 13.C);

- Remover o tecido gengival e curetar os tecidos de granulação com o auxílio de lâminas de bisturi e com o uso de curetas Goldman Fox (Figura 13.C);

- Remodelar o osso, com osteotomia (cinzéis de Fedi, Wedelstaedt e Oschembein, ou broca 2173) e osteoplastia (cinzel de Rhodes/Buzer, ou brocas 1014/1016 HL). Deve-se iniciar pela osteoplastia, principalmente quando a espessura do tecido ósseo é excessiva. A osteotomia deve começar pelo lado da invasão das distâncias biológicas; se a invasão for ao redor de todo o dente, deve começar pelas faces interproximais, para a definição da curva parabólica do osso (Figura 13.D);

- Irrigar abundantemente (durante todo o procedimento);

- Suturar.

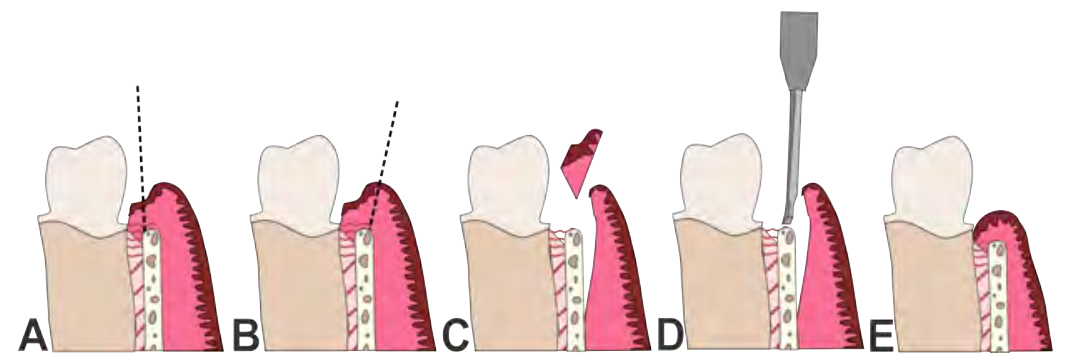

Figura 13: Retalho total sem bisel (A) e com bisel (B), descolamento do tecido epitelial e periósteo, e excisão do tecido gengival $(C)$, osteotomia e osteoplastia (D) resultado final (E).

\section{RETALHOS DE ESPESSURA PARCIAL}

Também chamados de retalhos mucosos ou divididos, estes incluem apenas o epitélio e uma camada de tecido conjuntivo 
subjacente, enquanto o osso permanece coberto por outra camada de tecido conjuntivo e periósteo (Carranza et al., 2016).

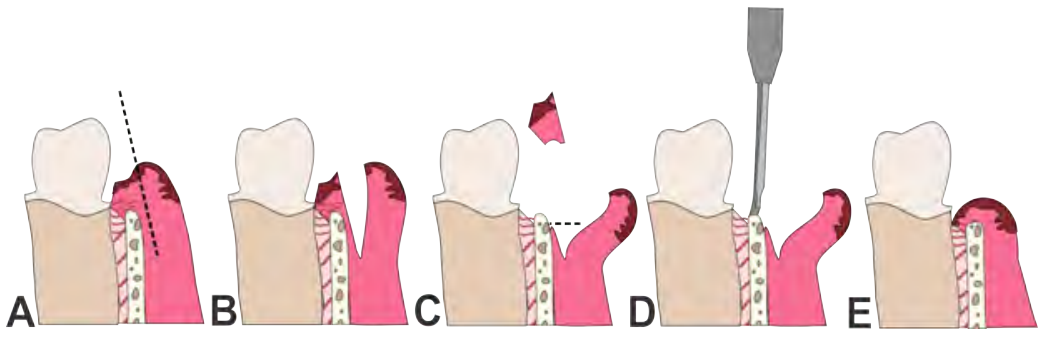

Figura 14: Incisão do retalho parcial (A), representando a preservação do periósteo e mucosa ceratinizada (B); excisão de tecido gengival para recontorno ósseo (C), osteotomia e osteoplastia (D) e resultado final (E).

\section{INDICAÇÕES}

Os retalhos mucosos são realizados quando há necessidade de reposicionamento lateral ou apical do retalho, devido à mobilidade da mucosa, pela presença de fibras elásticas. Nas cirurgias de ACC com finalidade restauradora, é recomendado quando há faixa estreita de mucosa ceratinizada e é necessária a confecção de um bisel para alongamento do dente, ou para expor a margem subgengival da restauração.

\section{TÉCNICA CIRÚRGICA}

- Anestesiar a região;

- Sondagem do dente e de seus adjacentes;

- Iniciar a incisão - intrasulcular (Figura 14.A);

- Dividir o retalho com lâmina de bisturi. A lâmina de bisturi segue até ultrapassar a junção mucogengival - isso 
deixará o retalho frouxo, em condições de ser deslocado mais apicalmente (Figura 14.B);

- Remover, com o auxílio de curetas Goldman Fox, tecido de granulação e tecido gengival ao redor, além de uma porção de periósteo, próximo à crista óssea para posterior osteotomia/osteoplastia (Figura 14.C);

- Remodelar o osso, com osteotomia e osteoplastia iniciar pela osteoplastia, principalmente quando a espessura do tecido ósseo é excessiva. A osteotomia deve ser iniciada pelo lado da invasão das distâncias biológicas; se a invasão for ao redor de todo o dente, deve iniciar pelas faces interproximais, para a definição da curva parabólica do osso (Figura 14.D);

- Irrigar abundantemente (durante todo o procedimento);

- Sutura tipo colchoeiro para fixar o retalho mais apicalmente no periósteo (Vide suturas periodontais Figura 25 e Figura 26).

\section{RETALHOS MISTOS}

Os retalhos mistos, também chamados de retalhos de Goldman, combinam retalhos totais e divididos na mesma técnica. (Joly et al., 2009) O retalho total é realizado na mucosa ceratinizada, enquanto o dividido é feito na mucosa alveolar. 

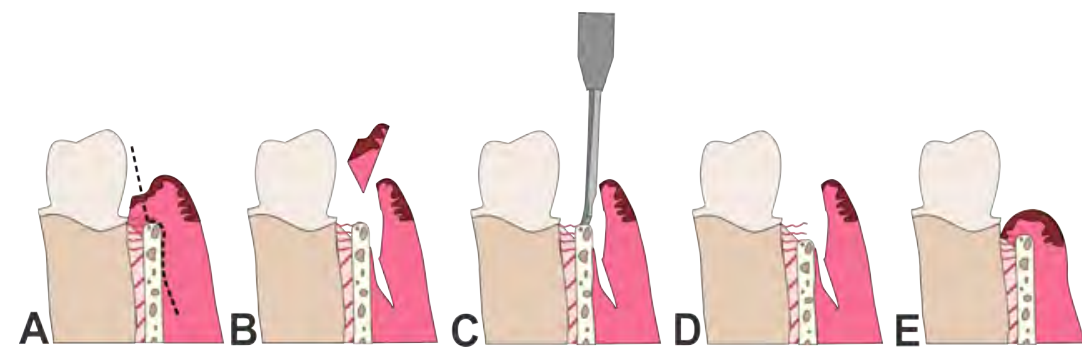

Figura 15: Retalho Misto. Incisão intrasulcular (A), descolamento total do retalho, incisão dividindo a mucosa alveolar e excisão de tecido (B), osteotomia e osteoplastia $(C)$ e resultado final $(E)$.

\section{INDICAÇÕES}

Os retalhos mistos são preconizados quando há faixa estreita de mucosa ceratinizada e, além disso, o tecido gengival é delgado.

\section{TÉCNICA CIRÚRGICA}

- Anestesiar a região;

- Sondagem do dente e de seus adjacentes;

- Iniciar a incisão - intrasulcular (Figura 15.A);

- Descolar todo o tecido mole com descolador de Molt, até a junção mucogengival;

- Dividir o retalho com lâmina de bisturi, a partir da junção mucogengival (Figura 15.B);

- Remover tecidos de granulação com o auxílio de curetas Goldman Fox;

- Remodelar o osso, com osteotomia e osteoplastia iniciar pela osteoplastia, principalmente quando a espessura do tecido ósseo é excessiva. A osteotomia deve ser iniciada pelo lado da invasão das distâncias biológicas; se a invasão for ao redor de todo o dente, 
deve iniciar pelas faces interproximais, para a definição da curva parabólica do osso (Figura 15.D);

- Irrigar abundantemente (durante todo o procedimento);

- Suturar o retalho mais para apical, no periósteo subjacente, para maior estabilidade.

\section{RETALHOS PALATINOS}

Como o palato é constituído de um tecido mais fibroso, os retalhos palatinos podem ser realizados de três formas: incisões intrasulculares, com bisel ou então, gengivectomia interna. Quando a invasão está nas faces proximais, indica-se o uso de incisão intrasulcular (Figura 16.A - 16.C); invasões na face palatina fazem com que seja necessária a realização de bisel (Figura 16.D - 16.F), ou então, havendo espessura tecidual considerável, opta-se pela gengivectomia interna (Figura 16.G 16.I). 

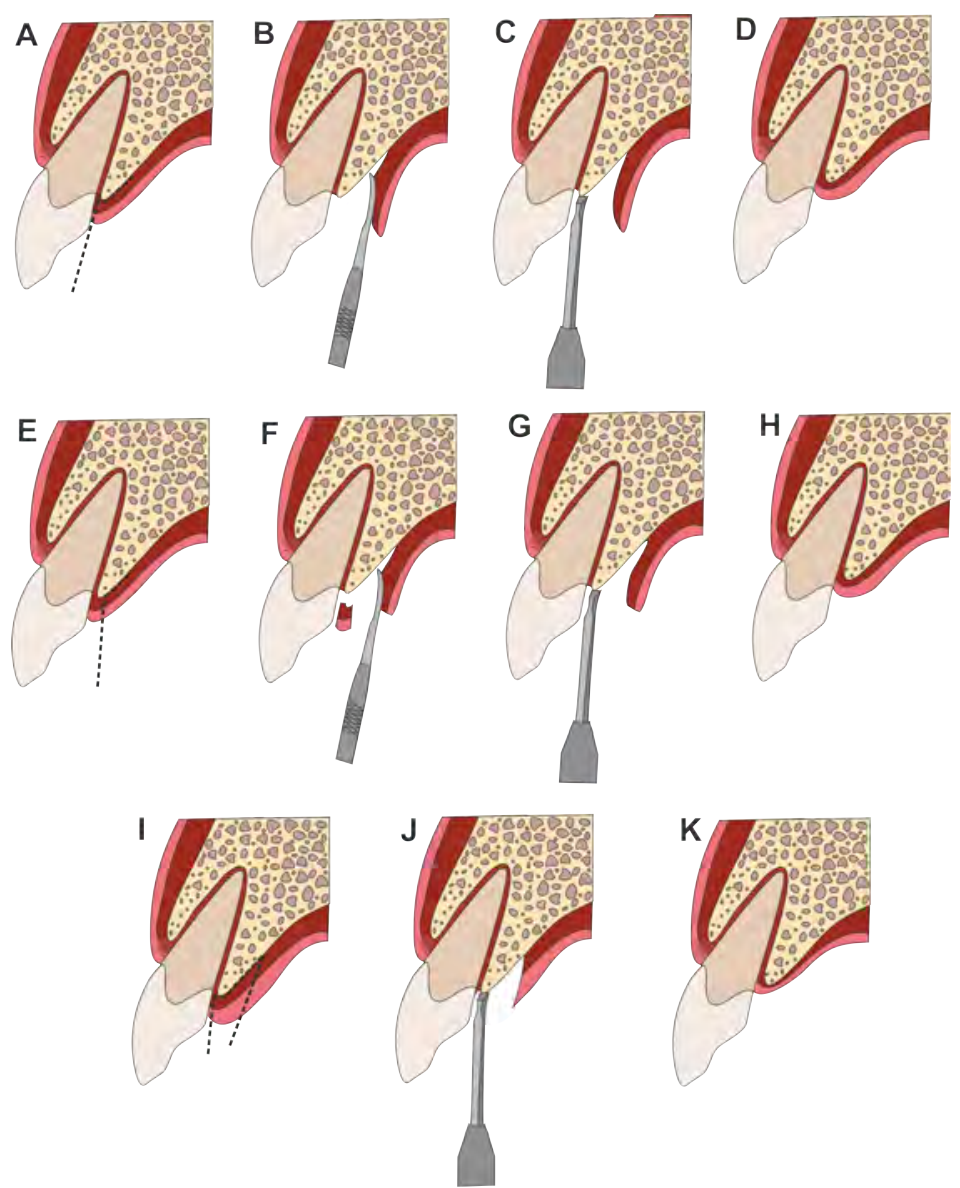

Figura 16: Retalhos Palatinos. Incisão intrasulcular (A) com retalho total (B) e osteotomia (C), incisão com bisel (D) e retalho total $(E)$ e osteotomia (G), e gengivectomia interna (G) e osteotomia (J).

\section{TÉCNICAS CIRÚRGICAS PARA ACC COM FINALIDADE RESTAURADORA}

A gengivectomia/gengivoplastia é uma das técnicas utilizadas para a realização do aumento de coroa clínica com finalidade restauradora, quando há mucosa ceratinizada suficiente e pelo 
menos $3 \mathrm{~mm}$ entre a crista óssea alveolar e a margem saudável da estrutura do dente.

Em relação aos retalhos periodontais, os mais indicados para as cirurgias de ACC são: retalho total com e sem bisel, retalho de Goldman (retalho misto) e retalho dividido. A indicação de cada retalho depende das condições da área dentogengival.

\section{GENGIVECTOMIA DE BISEL EXTERNO}

Consiste na excisão gengival, por meio de remoção da gengiva em altura (Genco et al., 1997). Esta técnica foi considerada como o procedimento pioneiro para tratamento da bolsa periodontal, entretanto, para este fim, tornou-se um procedimento obsoleto.

A literatura que antecedeu as técnicas de gengivectomia atual não tinha preocupação em preservar a mucosa ceratinizada componente da mucosa mastigatória que contorna os dentes, com função de resistir, principalmente, aos esforços mastigatórios (Duarte, 2009). Assim, Nabers, (1954), e Oschembein, (1960), introduziram o conceito da preservação mínima de mucosa ceratinizada para a gengivectomia.

A mucosa ceratinizada encontra-se firmemente aderida à superfície dentária subjacente e ao osso e é formada por fibras colágenas e tecido conjuntivo fibroso, enquanto a mucosa alveolar é rica em fibras elásticas, formando um tecido mais frouxo (Figura 17). (Ochsenbein, 1960)

Dessa forma, a preservação de mucosa ceratinizada é primordial para uma boa homeostasia marginal, conferindo proteção e estabilidade para a área cirúrgica. (Ochsenbein, 1960). 


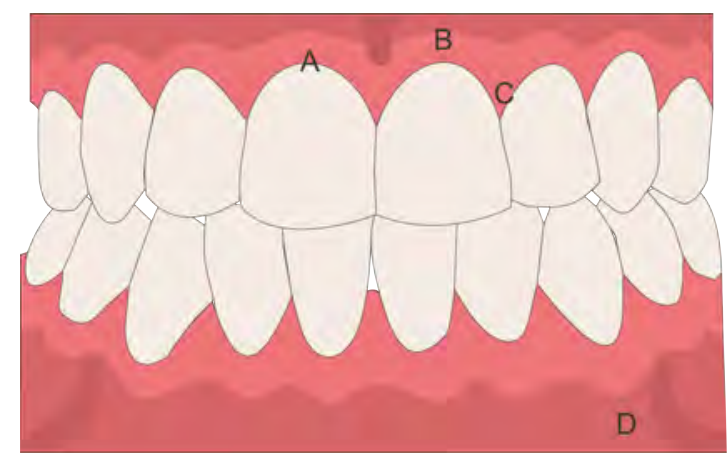

Figura 17: Periodonto de Proteção. Representação da mucosa gengival livre $(A)$, gengiva inserida $(B)$, papila interdentária $(C)$ e mucosa alveolar (D).

\section{GENGIVOPLASTIA}

Consiste no recontorno da gengiva para criar contornos gengivais fisiológicos. Remoção de tecido gengival em espessura (Genco et al., 1997). O termo gengivectomia/gengivoplastia é usualmente utilizado, por serem técnicas intimamente associadas.

INDICAÇÕES

ATUAIS

DA GENGIVECTOMIA/GENGIVOPLASTIA (Duarte, 2009)

- Crescimento gengival (medicamentoso, idiopático ou inflamatório);

- Correção de defeitos gengivais (exemplo: sequela de GUN);

- Aumento ou exposição de coroa clínica, quando não é necessário acesso ao tecido ósseo (Cardoso \& Gonçalves, 2002). 


\section{CONDIÇÕES PARA A EXECUÇÃO DA TÉCNICA}

- Quantidade suficiente de mucosa ceratinizada (Nabers, 1954);

- Tecido gengival fibroso e firme (Duarte, 2009);

- Tecido ósseo regular.

\section{CONTRA-INDICAÇÕES}

- Necessidade de cirurgia óssea ou exame da forma e morfologias ósseas;

- Pequena quantidade de mucosa ceratinizada;

- Vigência de infecções agudas;

- Higiene bucal insatisfatória.

TÉCNICA CIRÚRGICA (Duarte, 2009)

- Anestesiar com técnica infiltrativa, no fundo de vestíbulo, próximo à linha mucogengival (Figura 19.A e Figura 20.A);

- Sondar a área para verificar o tamanho do sulco ou falsa bolsa (Figura 19.B e Figura 20.B);

- Marcar externamente, com sonda periodontal, a profundidade (pontos sangrantes), para delinear o curso da área a ser excisada (Figura 19.C e Figura 20.C);

- Realizar a incisão primária, com gengivótomo de Kirkland (Figura 19.D e Figura 20.D);

De acordo com Passanezi et al. (2011):

a) Tecido gengival fino (até $1,5 \mathrm{~mm}$ ): $\mathrm{A}$ incisão deve ser realizada a 0,5 a $1 \mathrm{~mm}$ apical ao ponto 
sangrante, com angulação de $30^{\circ} \mathrm{com}$ o longo eixo do dente (Figura 18.A).

b) Tecido gengival de espessura média (1,5 a 3 $\mathrm{mm}$ ): Incisão inicia de 2 a $3 \mathrm{~mm}$ apical ao ponto sangrante com angulação aproximadamente de $45^{\circ}$ (Figura 18.B).

c) Tecido com espessura acima de $3 \mathrm{~mm}$ e até 5 $\mathrm{mm}$ : Incisão de 3 a $6 \mathrm{~mm}$ apical ao ponto sangrante com angulação de $60^{\circ}$ (Figura 18.C).

Ainda, um tecido com espessura superior a $5 \mathrm{~mm}$, a técnica mais conveniente a ser realizada é a gengivectomia de bisel interno.

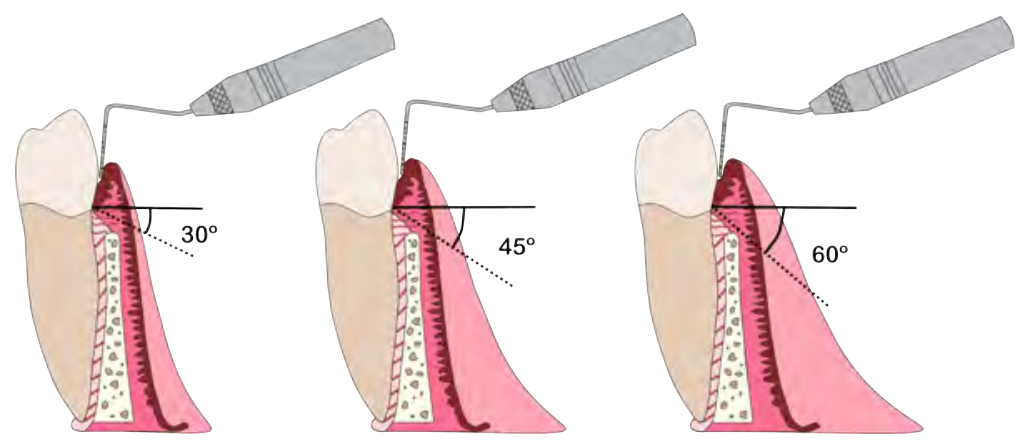

Figura 18: Angulações da gengivectomia/gengivoplastia.

- Iniciar incisão secundária, que complementa a primeira, realizada nos espaços interproximais, seguindo a mesma inclinação, com gengivótomo de Orban (Figura 19.E e Figura 20.E);

- Remover o colar de gengiva excisado e depois o tecido de granulação, com o auxílio de curetas Goldman Fox, sempre irrigação com soro fisiológico (Figura 19.F e Figura 20.F);

- Remodelação do contorno gengival (gengivótomos, tesouras curvas ou alicate para tecido): o objetivo é 
deixar o contorno gengival mais fino e consequentemente mais estético e fisiológico (Figuras 19.G, 19.H, 20.G e 20.H).

A espessura tecidual pode ser avaliada por meio de tomografia computadorizada, utilizando afastador labial. Além disso, pode ser calculada com a utilização de uma agulha de anestesia com cursor - a agulha é introduzida perpendicularmente ao tecido gengival e depois é medida com uma régua. 

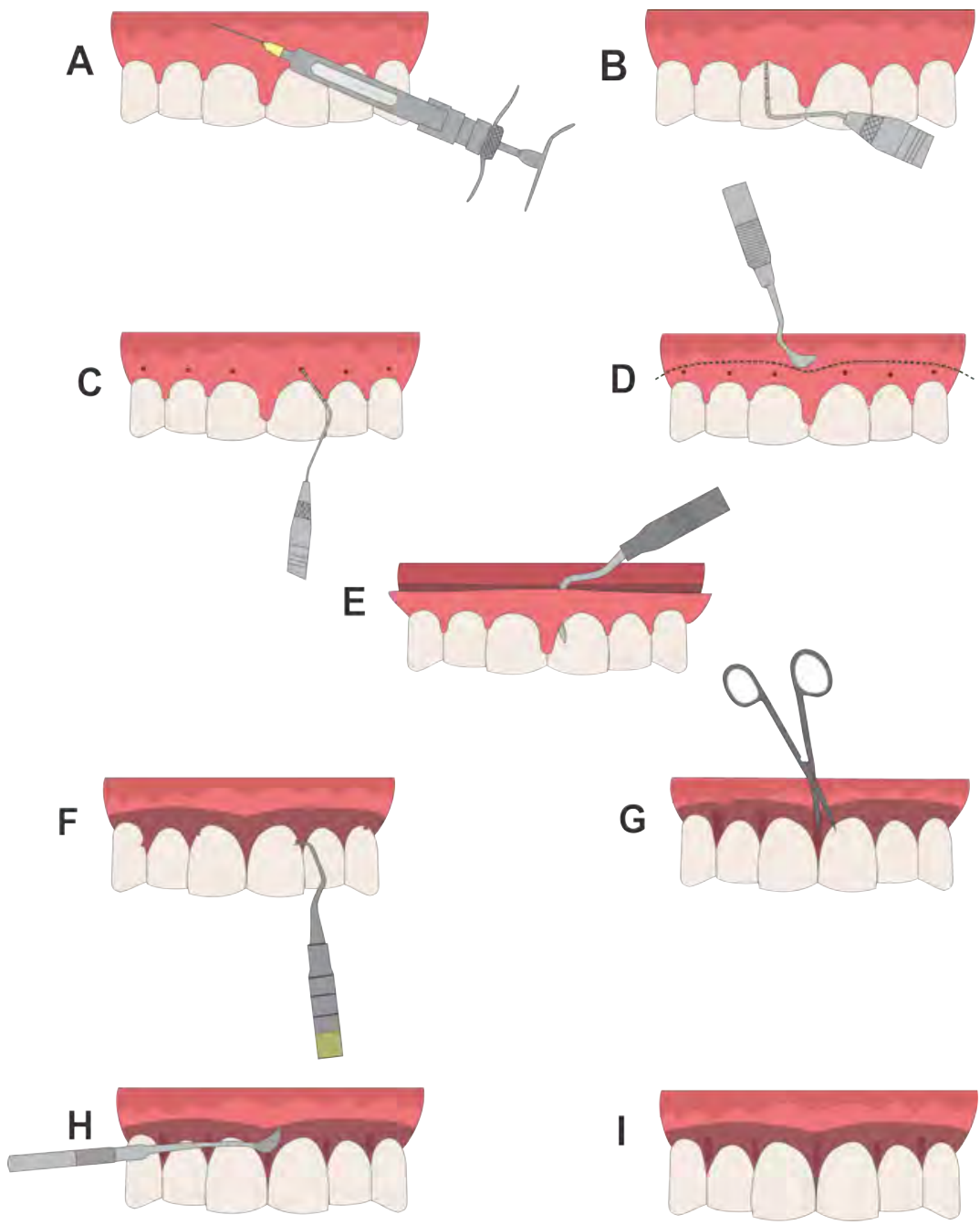

Figura 19: Gengivectomia/Gengivoplastia na arcada superior. Anestesia em fundo de vestíbulo (A), sondagem (B), realização dos pontos sangrantes $(C)$, representação da incisão primária com gengivótomo de Kirkland (D), incisão secundária com gengivótomo de Orban (E), curetagem dos tecidos de granulação $(F)$, realização dos sulcos de escape com micro-tesoura $(G)$, regularização da espessura gengival com gengivótomo de Kirkland $(\mathrm{H})$ e resultado final $(\mathrm{I})$. 

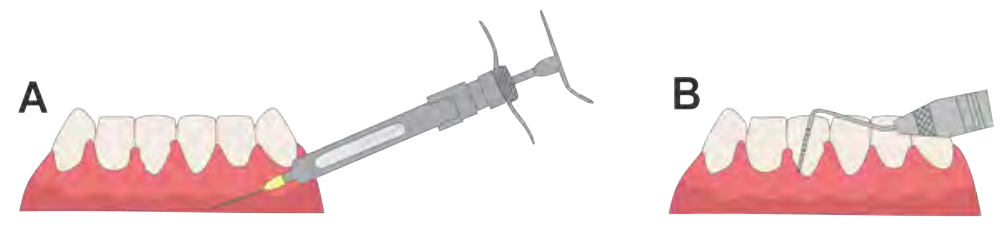

C

D
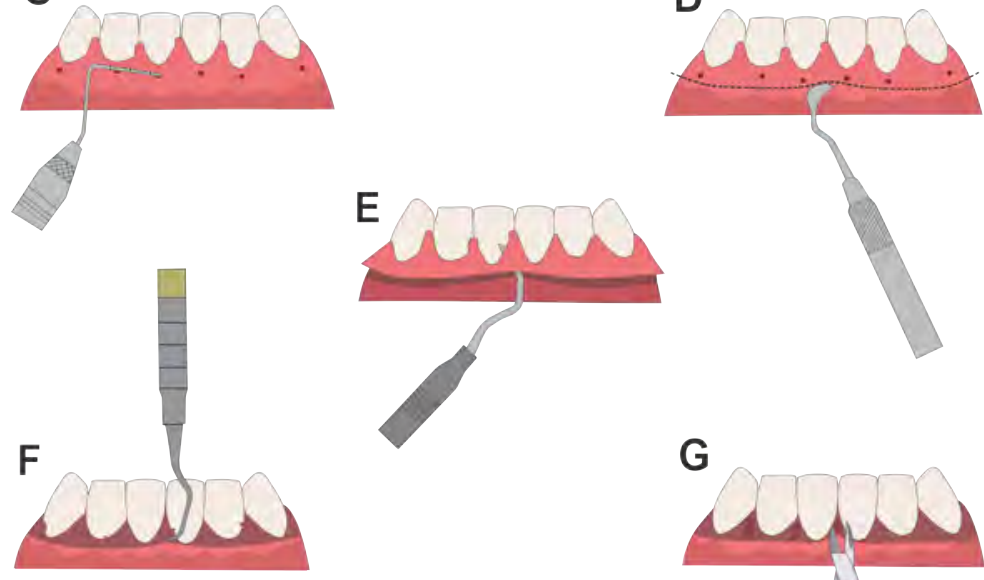

G

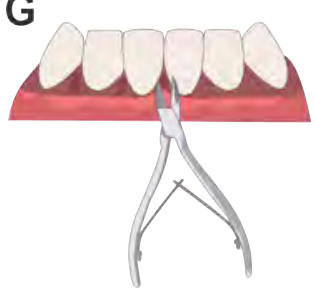

$\mathrm{H}$
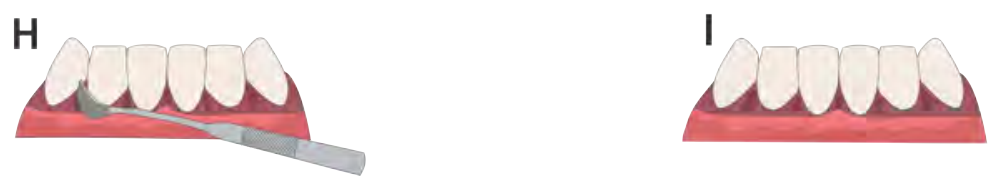

Figura 20: Gengivectomia/Gengivoplastia na arcada inferior. Anestesia em fundo de vestíbulo $(A)$, sondagem $(B)$, realização dos pontos sangrantes $(C)$, representação da incisão primária com gengivótomo de Kirkland (D), incisão secundária com gengivótomo de Orban (E), curetagem dos tecidos de granulação $(F)$, realização dos sulcos de escape com alicate para tecido $(G)$, regularização da espessura gengival com gengivótomo de Kirkland $(\mathrm{H})$ e resultado final $(\mathrm{I})$. 


\section{OSTEOTOMIA}

Quando as distâncias biológicas são invadidas, realiza-se a osteotomia, que consiste em uma remoção de tecido ósseo de suporte em altura - tecido envolvido diretamente na sustentação dos dentes - para recuperar as medidas definidas pelo espaço biológico. (Cardoso \& Gonçalves, 2002)

Clinicamente, $3 \mathrm{~mm}$ são considerados suficientes para restabelecer as distâncias biológicas, envolvendo desde a crista óssea alveolar até a margem saudável da estrutura dentária a ser restaurada. (Cardoso \& Gonçalves, 2002)

Para realização da osteotomia, podem ser utilizados instrumentais manuais e rotatórios. Em relação aos rotatórios, devem ser utilizados sob irrigação constante, para diminuir sequelas aos tecidos.

\section{OSTEOPLASTIA}

Friedman, em 1955, introduziu este termo para descrever um procedimento que tem como objetivo criar um contorno fisiológico do osso alveolar, sem a remoção de tecido ósseo de suporte, ou seja, consiste em uma remoção de osso em espessura. (Lindhe et al., 2011)

A osteoplastia, sempre associada à osteotomia, auxilia no refinamento de bordas ósseas espessas. Além disso, facilita um recobrimento mucoso adequado, uma vez que propicia redução óssea ao se esculpir sulcos verticais de escape. (Lindhe et al., 2011) 


\section{TÉCNICA CIRÚRGICA DA OSTEOTOMIA/OSTEOPLASTIA}

- Após confecção do retalho e visualização do tecido ósseo, iniciar a técnica pela osteoplastia, se houver espessura óssea considerável - preparam-se os sulcos verticais de escape, com instrumentais rotatórios (brocas $1014 \mathrm{HL}$ ou $1016 \mathrm{HL}$ ) ou manuais (cinzel de Rhodes ou Buzer) (Figura 21.C);

- Osteoplastia para diminuição de espessura óssea com cinzel de Rhodes (Figura 21.D);

- Realizar a osteotomia, iniciando por onde se encontra a invasão das distâncias biológicas, com cinzel de Fedi (Figura 21.E);

- Osteotomia com instrumentais rotatórios (broca 2173) (Figura 21.F);

- Irrigar abundantemente (durante todo o procedimento), principalmente na utilização de instrumentais rotatórios, para não lesionar os tecidos;

- Suturar.

A
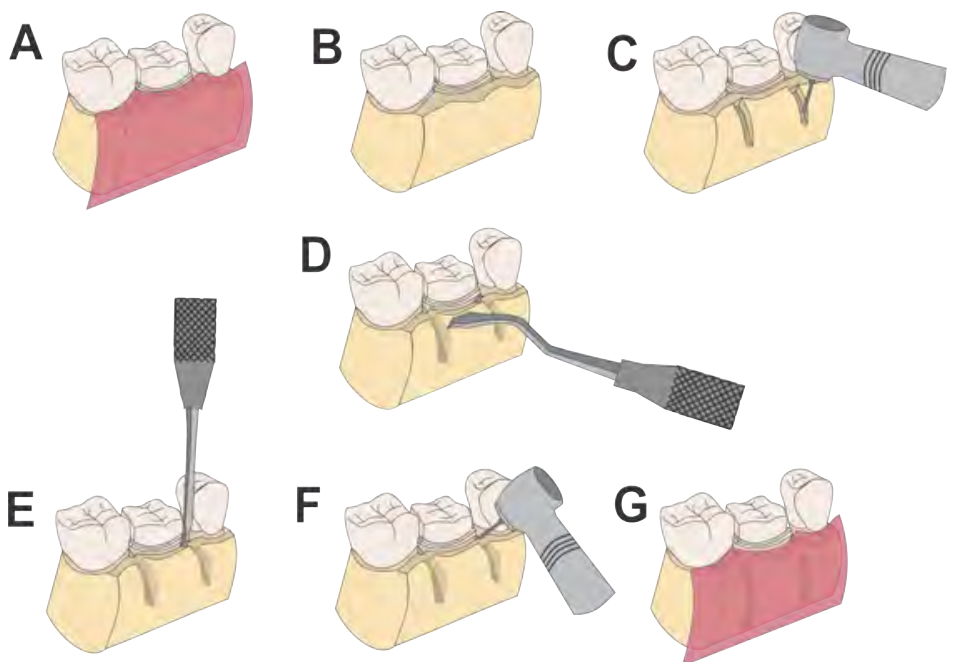

D
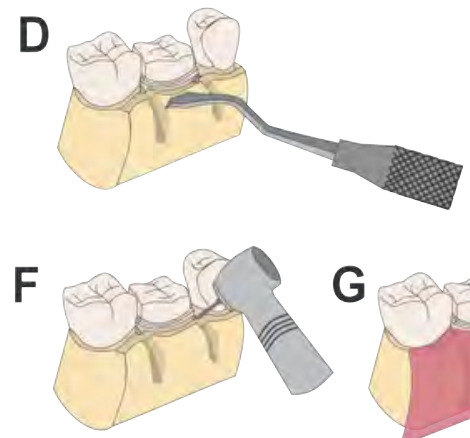

G

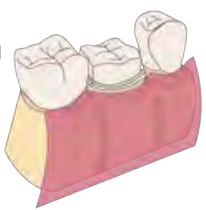

Figura 21: Osteotomia/Osteoplastia. Visualização de preparo subgengival (A e B), osteoplastia com broca $1014 \mathrm{HL}$ ou $1016 \mathrm{HL}$ (C), 
osteoplastia na face vestibular com cinzel de Rhodes (D), osteotomia com cinzel de Fedi (E) e com broca 2173 (F). Depois, resultado final (G).

\section{CURA DA FERIDA CIRÚRGICA APÓS TERAPIA PERIODONTAL}

As várias formas terapêuticas para cura da doença periodontal causam trauma aos tecidos epitelial e conjuntivo, que se reconstroem por regeneração e reparo tecidual.

O reparo faz com que tecidos similares aos tecidos perdidos sejam formados. Este processo sucede-se quando a regeneração completa do periodonto não se torna viável. Neste processo de cura ocorre a diminuição da profundidade de sondagem após tratamento de defeitos tanto supra-ósseos como infra-ósseos, com formação de epitélio juncional longo, contrariamente à regeneração periodontal (Genco et al., 1997; Caton et al., 1980). O epitélio juncional longo é formado quando não há o restabelecimento total dos componentes do periodonto de sustentação. O reparo paralisa a destruição de tecido ósseo, mas não resulta em ganho de altura óssea ou inserção gengival. (Carranza et al., 2016)

$\mathrm{Na}$ regeneração ocorre nova formação de cemento, inserção, osso alveolar e até mesmo ligamento periodontal nas áreas em que essas estruturas haviam sido perdidas. Além disso, acontece o restabelecimento funcional da orientação das fibras gengivais e a inserção do epitélio juncional ao dente. Para tanto, o uso de biomaterais ajudam na condução deste processo. (Genco et al., 1997)

$\mathrm{Na}$ cura da ferida cirúrgica após terapia periodontal, seja ressectiva ou conservadora, não se espera que ocorra a regeneração tecidual, apenas o reparo dos tecidos. 


\section{CURA DA FERIDA CIRÚRGICA PÓS- GENGIVECTOMIA/GENGIVOPLASTIA}

A resposta inicial cirúrgica constitui-se pela formação de um coágulo sanguíneo que protege a superfície. Enquanto isso, o tecido subjacente estabelece um quadro inflamatório agudo, com presença de necrose superficial (Ramfjord et al., 1966). Passados cinco dias, o coágulo é substituído por tecido de granulação (Innes, 1970). Cerca de duas semanas depois da cirurgia, os capilares do ligamento periodontal migram para o interior do tecido de granulação, ligando-se aos vasos sanguíneos gengivais (Watanabe \& Suzuki, 1963). Enquanto isso, o tecido de granulação cresce em direção coronal, estabelecendo assim uma nova margem gengival e um novo sulco gengival. (Carranza et al., 2016)

Após doze até 24 horas, ocorre a migração de células epiteliais, que alcança seu pico em dois dias (Ramfjord et al., 1966). Então, essas novas células migram para a ferida sobre uma camada de fibrina que é reabsorvida e substituída por tecido conjuntivo (Innes, 1970). A reparação epitelial completa dura em torno de um mês, enquanto a conjuntiva dura cerca de sete semanas (Stanton et al., 1969).

\section{CURA PÓS-CIRURGIA A RETALHO}

De imediato, após a sutura, um coágulo sanguíneo faz uma conexão entre o retalho e o dente ou a superfície óssea. A partir do segundo dia, as células epiteliais migram até as bordas do retalho, enquanto a adaptação entre o retalho e o osso alveolar promove uma resposta inflamatória. (Caffesse et al, 1968)

Após uma semana, o coágulo formado é substituído por tecido de granulação, advindo do tecido conjuntivo gengival, do ligamento periodontal e da medula óssea (Caffesse et al., 1968). Depois de 
um mês, o sulco gengival encontra-se epitelizado, assim como o arranjo funcional inicial das fibras colágenas supra-ósseas. (Carranza et al., 2016)

\section{CURA PÓS-OSTEOTOMIA E OSTEOPLASTIA}

A cura após remodelação óssea se inicia pela inserção do tecido conjuntivo ao osso de quatorze a 21 dias depois da cirurgia. A maturação e remodelação óssea, realizada pelos osteoblastos e osteoclastos, perdura por até seis meses. Aconselha-se, dessa forma, aguardar pelo menos seis semanas para o início de algum procedimento restaurador após osteotomia e osteoplastia, para restabelecimento completo dos tecidos gengivais e tecido ósseo (Carranza et al., 2016). No entanto, para que se coloque um preparo dentário subgengivalmente, é necessário que ocorra a formação completa do sulco gengival.

\section{SUTURAS PERIODONTAIS}

O objetivo das suturas é guiar a cura dos tecidos, colocando-os de maneira adequada, até que estes tenham condições de guiar sua própria cura (Carranza et al., 2016).

São algumas finalidades da sutura (Grossi et al., 1971/1972; Edwab, 1995):

- Aproximar as bordas da ferida cirúrgica;

- Prevenir sangramentos e dores pós-operatórios;

- Ajudar na formação do coágulo sanguíneo, permitindo que ele se mantenha na área cirúrgica;

- Manter o tecido justaposto ao osso, para facilitar o processo de cicatrização; 
- Impedir a entrada de corpos estranhos na ferida.

Para uma adequada qualidade na sutura é necessário que se tenha um bom manejo dos instrumentais e da técnica cirúrgica, boa compatibilidade entre o tecido e o material utilizado e força de tensão adequada do material, além de elasticidade, para evitar isquemia dos tecidos. (Koshak, 2017)

A agulha deve penetrar os tecidos em um ângulo reto, de 2 a 3 milímetros da borda da incisão, utilizando um porta-agulha. A agulha então deve atravessar o tecido, acompanhando sua angulação (Koshak, 2017). O nó é atado depois de finalizada a sutura e não deve ser colocado sobre a incisão. (Carranza et al., 2016)

SUTURA PROXIMAL DE LAÇO SIMPLES (Carranza et al., 2016)

Possibilita um fechamento adequado da papila interdental, é utilizada quando é necessária a justaposição dos retalhos vestibular e lingual/palatino.

1. A agulha atravessa a superfície epitélio-conjuntivo do primeiro retalho (Figura 22.A) ;

2. Depois, atravessa a superfície conjuntivo-epitélio do retalho oposto (Figura 22.B);

3. O nó é atado quando a sutura retorna para o primeiro retalho (Figura 22.D). 

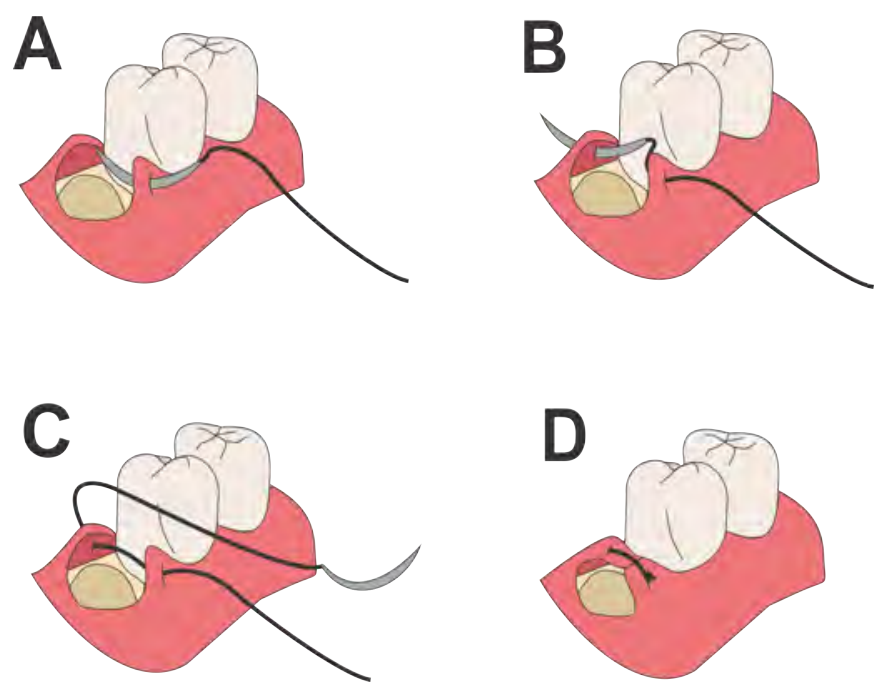

Figura 22: Sutura Proximal de Laço Simples.

SUTURA EM OITO (Carranza et al., 2016)

É utilizada quando os tecidos não estão devidamente posicionados, seja por um deslocamento apical do retalho ou por incisões não escalonadas.

1. A agulha atravessa a superfície epitélio-conjuntivo do primeiro retalho (Figura 23.A);

2. A superfície epitélio-conjuntivo do segundo retalho é atravessada (Figura 23.B);

3. O nó é atado quando a sutura retorna para o primeiro retalho (Figura 23.D). 

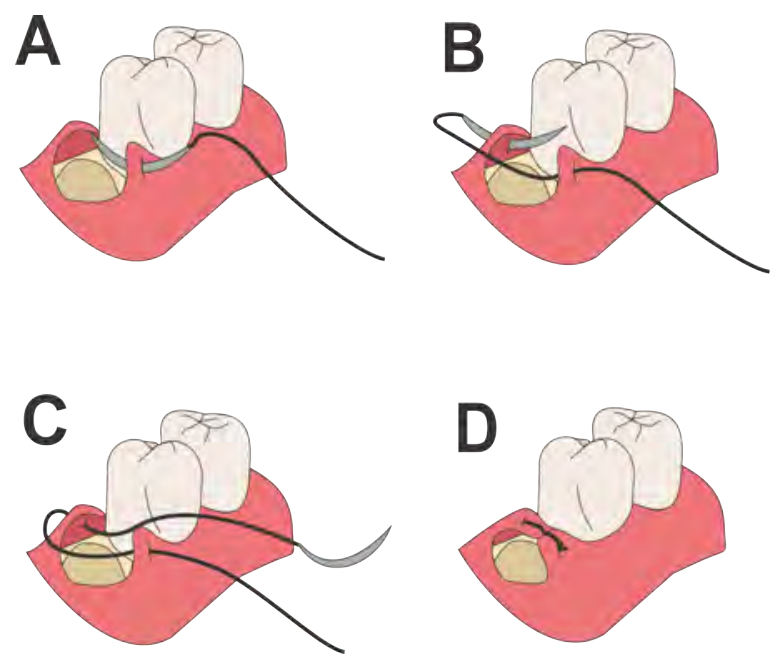

Figura 23: Sutura em Oito.

SUTURA SUSPENSÓRIA (Carranza et al., 2016)

Este tipo de sutura une o retalho vestibular ao dente e o palatino ou lingual ao dente. Feitos de forma independente.

1. A agulha penetra a superfície epitélio-conjuntivo do retalho (Figura 24.A);

2. A sutura envolve o dente (Figura 24.B);

3. A superfície epitélio-conjuntivo do mesmo retalho (da área interdental adjacente) é penetrada (Figura 24.C);

4. A sutura retorna ao ponto inicial, onde ata-se o nó (Figura 24.D). 

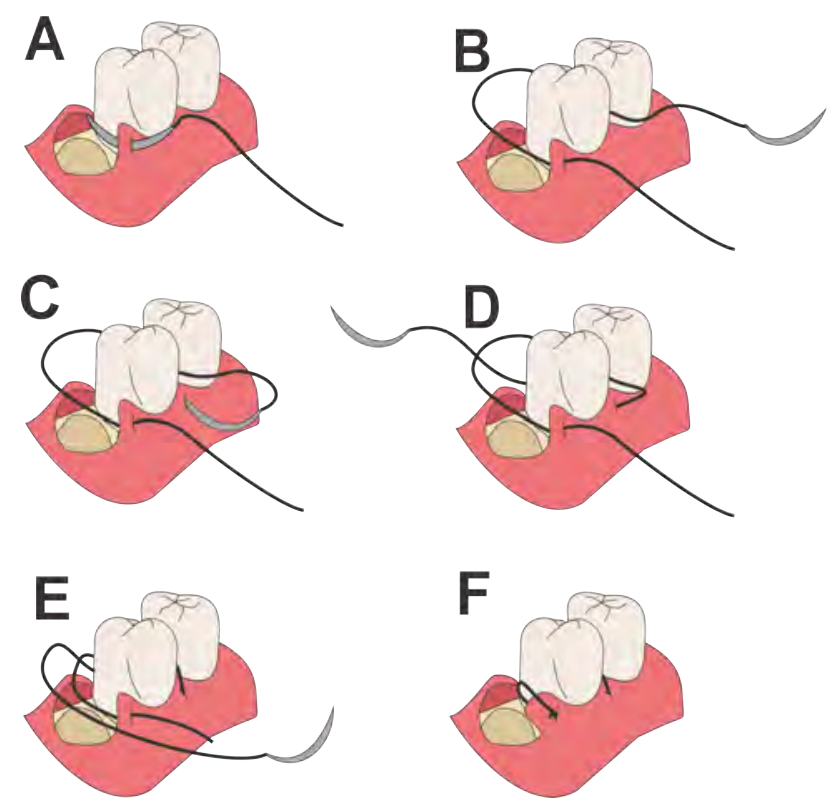

Figura 24: Sutura Suspensória.

SUTURA COLCHOEIRO HORIZONTAL INTERNA (Koshak, 2017)

As suturas em colchoeiro horizontal são frequentemente utilizadas quando o objetivo é aproximar as margens do tecido incisado, impossibilitando que estas se invertam durante 0 processo de cura.

1. A agulha atravessa o primeiro retalho pela superfície epitélio-conjuntivo (Figura 25.A);

2. A superfície conjuntivo-epitélio do segundo retalho é perfurada (Figura 25.B);

3. Perfura-se o segundo retalho novamente, pela superfície epitélio-conjuntivo, horizontalmente à primeira perfuração (Figura 25.C); 
4. O primeiro retalho é atravessado pelo lado conjuntivoepitélio, também horizontalmente (Figura 25.D);

5. O nó é atado no primeiro retalho (Figura 25.E).
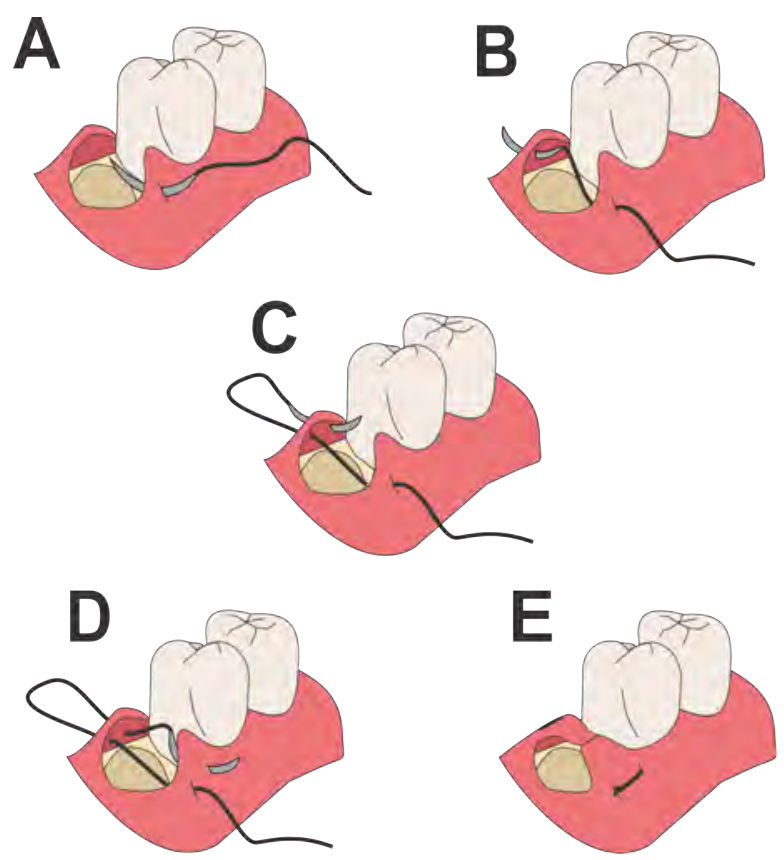

Figura 25: Sutura Colchoeiro Horizontal Interna.

SUTURA COLCHOEIRO VERTICAL INTERNA (Koshak, 2017)

Esta sutura é semelhante à do colchoeiro horizontal interna, diferindo apenas pelo fato das duas perfurações em cada papila estarem em sentido vertical, ao invés de horizontal.

É utilizada para não coaptar feridas mais profundas, pois atravessa o retalho em dois níveis, um mais superficial e outro mais abaixo, promovendo uma melhor adaptação do retalho. 

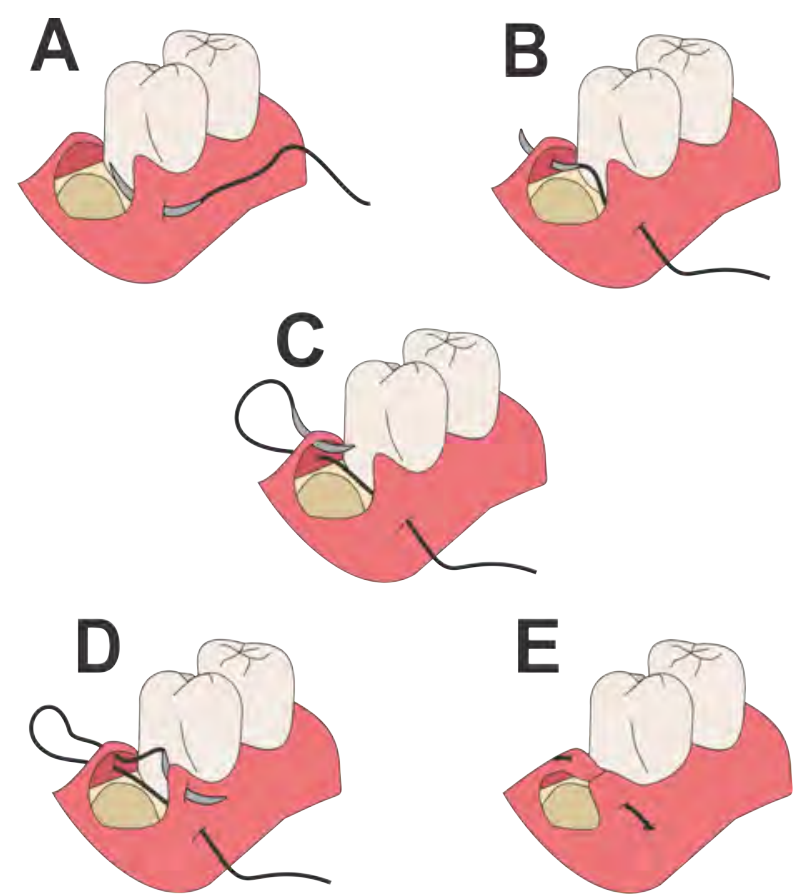

Figura 26: Sutura Colchoeiro Vertical Interna. Penetração da agulha na parte externa do primeiro retalho (A), depois na parte interna do segundo retalho (B). Então, a agulha entra em uma posição vertical mais acima da (B) também no segundo retalho, assim como no primeiro (D), e o nó é atado no ponto inicial (E).

\section{NÓS PERIODONTAIS}

\section{NÓ QUADRADO}

O nó quadrado é constituído por dois laços simples, gerados em direções opostas. Este tipo de nó promove grande estabilidade interna e é ideal para o fechamento passivo de feridas cirúrgicas. Além disso, ele mantém suporte nas bordas da ferida, sem causar demasiada tensão (Carranza et al., 2016). 


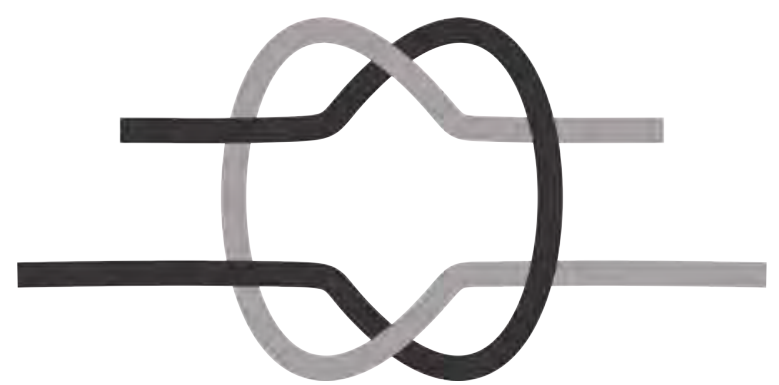

Figura 27: Nó quadrado. Cada cor - cinza e preto - representa uma ponta do fio.

\section{INSTRUMENTAIS CIRÚRGICOS}

Vários são os instrumentais utilizados para a realização das cirurgias periodontais, cada um com sua finalidade. São alguns deles:

\section{CINZÉIS}

Imagem 1: Cinzel de Fedi. Utilizado para osteotomia de faces livres. (Fonte: Site QualiDental)

Imagem 2: Cinzel de Wedelstaedt. Usado para osteotomia de faces interproximais. (Fonte: Site HuFriedy)

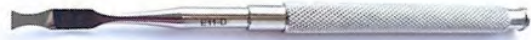


Imagem 3: Cinzel de Oschsenbein. Usado para osteotomia de faces livres. (Fonte: Site DentalAccess)

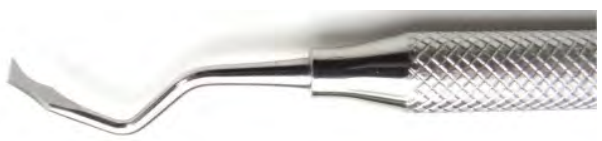

Imagem 4: Cinzel de Rhodes ou Buzer. Utilizado para osteoplastia de faces livres. (Fonte: Site QualiDental)

\section{CURETAS}

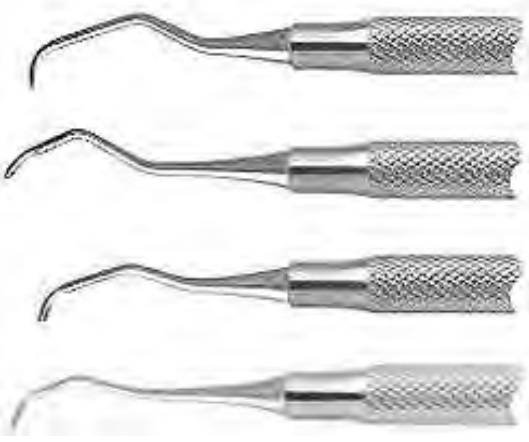

Imagem 5: Curetas Goldman Fox. Usadas para curetagem dos tecidos de granulação. (Fonte: Site AdmasMedical)

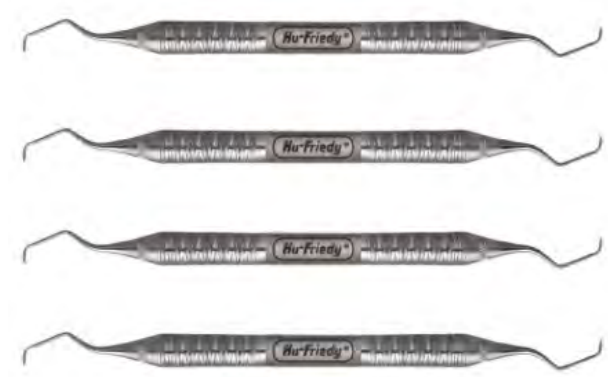

Imagem 6: Curetas Gracey. Realizam raspagem e alisamento radicular. (Fonte: Site NovaEndoVita) 


\section{GENGIVÓTOMOS}

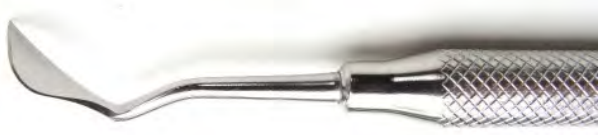

Imagem 7: Gengivótomo de Kirkland. Usado para gengivectomia/gengivoplastia. (Fonte: Site Nittinox)

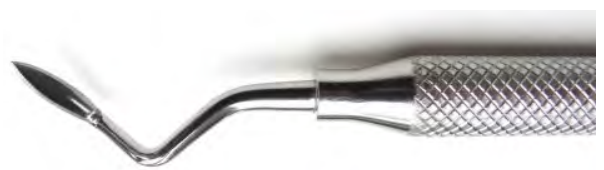

Imagem 8: Gengivótomo de Orban. Realizam gengivectomia nas faces interproximais. (Fonte: Site BioDental)

\section{BROCAS}

Imagem 9: Broca 1014 HL. Usada para osteoplastia. (Fonte: Site DentalOrtoline)

Imagem 10: Broca $1016 \mathrm{HL}$. Usada para osteoplastia. (Fonte: Site DentalOutlet)

Imagem 11: Broca 2173. Usada para osteotomia/osteoplastia. (Fonte: DentalBorges) 


\section{OUTROS INSTRUMENTAIS}

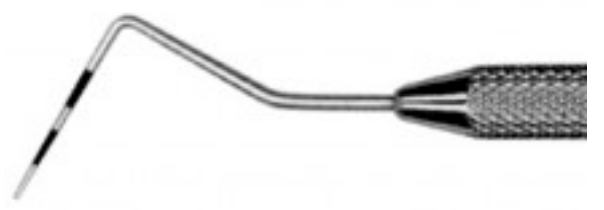

Imagem 17: Sonda Periodontal. Usada para delimitar as profundidades de sondagem. (Fonte: Site Dental Express)

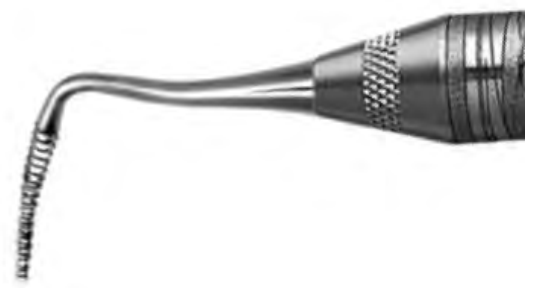

Imagem 16: Lima Schluger. Utilizada para osteotomia em faces interproximais. (Fonte: Site Bless Odontologia)

Imagem 12: Descolador de Molt (Cureta 2-4). Utilizado para descolar e afastar tecido mole. (Fonte: Site QualiDental)

\section{І111111I}

Imagem 13: Pinça Dietrich. (Fonte: Site DesignOral)

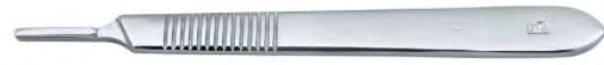

Imagem 14: Cabo para bisturi. (Fonte: Site DentalCremer) 


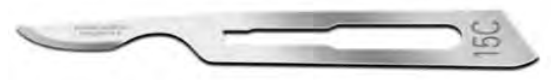

Imagem 15: Lâmina de bisturi descartável número 15C. Utilizada para a realização de incisões. (Fonte: Site SuryaDental)

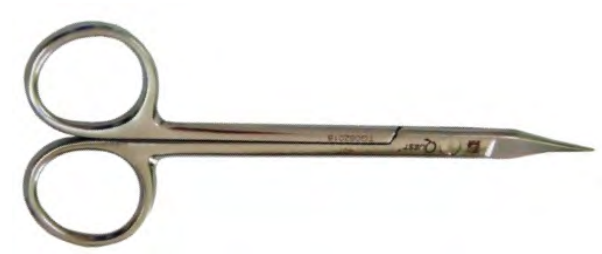

Imagem 16: Tesoura Goldman Fox. (Fonte: Site DesignOral)

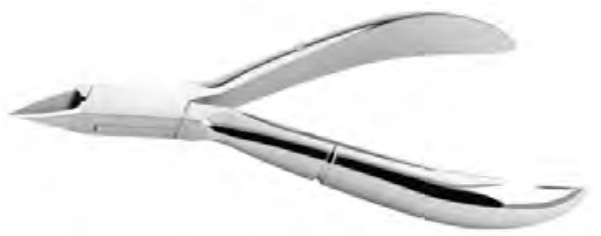

Imagem 17: Alicate para tecido. Usado para reprodução dos sulcos de escape na gengivoplastia. (Fonte: Site Shinsei)

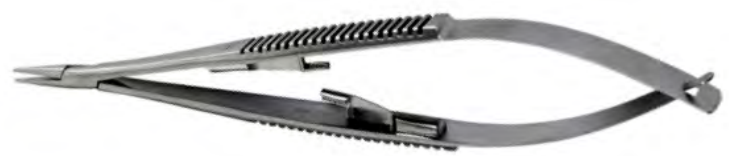

Imagem 18: Porta-agulha Castroviejo. Utilizado para sutura. (Fonte: Site FibraCirúrgica)

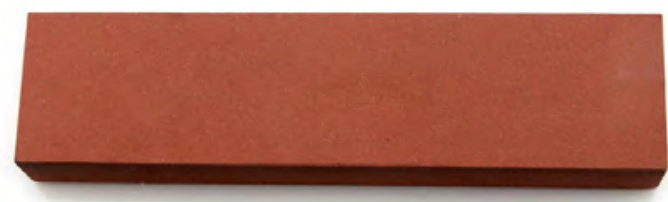


Imagem 19: Pedra de afiar, usada para afiar as bordas cortantes dos instrumentais. (Fonte: Site Zakharov)

\section{CONSIDERAÇÕES FINAIS}

As cirurgias periodontais foram idealizadas há muitos anos, quando ainda não havia o conhecimento e entendimento acerca da existência dos microrganismos e seus mecanismos de ação. Por isso, com o tempo, as técnicas cirúrgicas passaram por grandes mudanças, principalmente com a concepção de uma Odontologia cada vez menos invasiva e mais estética.

As mudanças de paradigma em relação ao tratamento cirúrgico da bolsa periodontal ressalta a diferença da finalidade deste tipo de tratamento no cotidiano clínico nos dias de hoje. Diferentemente de antes, as bolsas periodontais são tratadas prioritariamente com técnicas conservadoras, como a raspagem e alisamento radicular, associadas às consultas de manutenção periodontal e o aperfeiçoamento da higiene bucal por parte do paciente.

Antigamente, optava-se pelos tratamentos ressectivos, em que eram realizadas excisões de tecido mole, assim como de tecido ósseo. Acreditava-se que esses tratamentos eram indispensáveis para a cura da doença periodontal e para a eliminação da bolsa periodontal. Além disso, tinham como finalidade a devolução das distâncias biológicas em limites considerados ideais e consequentemente mais fisiológicos. Entendia-se que a eliminação cirúrgica da bolsa evitaria a recidiva da doença periodontal.

Com o decorrer dos anos, observou-se então, através de estudos, que a eliminação de patógenos e de placa bacteriana é suficiente, muitas vezes, para a cura de uma inflamação ou processo infeccioso nos tecidos periodontais, adicionalmente à terapia de suporte periodontal, que trouxe um novo entendimento a respeito 
do controle da doença periodontal. Dessa forma, é essencial que se enfatize a relevância da terapia periodontal de suporte e do controle da placa para uma boa saúde periodontal.

Contudo, quando o tratamento conservador, como a raspagem e alisamento radicular não são suficientes, as diversas técnicas cirúrgicas, quando devidamente empregadas, possibilitam a cura dos tecidos periodontais. Adicionalmente, quando há invasão das distâncias biológicas, as cirurgias de aumento de coroa clínica com finalidade restauradora são bastante utilizadas para restabelecer essas distâncias, possibilitando a reabilitação por meio de próteses e restaurações.

Já em casos de devolução da estética gengival, procedimentos cirúrgicos a retalho associados com osteoplastia/osteotomia ou emprego de gengivectomia/gengivoplastia são recomendados. Logo, todos os procedimentos retratados neste manual têm o objetivo de auxiliar para uma melhor compreensão e execução das técnicas, de maneira ilustrativa e objetiva, já que podem ser utilizados em conjunto para uma mesma finalidade, além de serem procedimentos frequentes no cotidiano clínico.

\section{REFERÊNCIAS BIBLIOGRÁFICAS}

1. Ariaudo AA, Tyrrell HA. Repositioning and Increasing the Zone of Attached Gingiva. J Periodontol 1957 Abr; 28(2): 106-110.

2. Baratieri LN, Júnior SM, de Melo TS, Ferreira KB, Hilgert LA, Schlichting $\mathrm{LH}$, et al. Odontologia Restauradora: Fundamentos e Técnicas. São Paulo: Santos; 2013.

3. Black GV. An investigation of physical characters of the human teeth in relation of their diseases and to practical 
dental operations, together with the physical characters of filling-materials. Dent Cosmos 1895; 40: 353-421.

4. Brägger U, Lauchenauer $D$, Lang NP. Surgical Lengthening of the Clinical Crown. J Clinic Periodontol 1992; 19(1): 5863.

5. Caffesse RG, Ramfjord SP, Nasjleti CE. Reverse Bevel Periodontal Flaps in Monkeys. J Periodontol 1968; 39(4): 219-35.

6. Cardoso RJA, Gonçalves EAN. Periodontia/Cirurgia para Implantes/ Cirurgia/ Anestesiologia. São Paulo: Artes Médicas Ltda; 2002.

7. Carranza FA, Newman MG, Takei H, Klokkedvold P. Periodontia Clínica. 12 ed. Rio de Janeiro: Elsevier; 2016.

8. Carranza FA. Periodontia clínica de Glickman. 2 ed. Rio de Janeiro: Interamericana; 1983.

9. Carvalho CV, Pinto RCNC, Souto MLS, Chambrone L, Soares FP, César-Neto JP, Pannuti CM, Romito GA. Espaço Biológico: conceito chave para estética e saúde gengival em procedimentos restauradores. Int $\mathrm{J}$ Periodontics Restorative Dent 2016; 1: 825-832.

10. Caton J, Nyman S, Zander H. Histometric evaluation of periodontal surgery II. Connective tissue attachment levels after four regenerative procedures. J Clin Periodontol 1980 Jun; 7(3): 224-31.

11. Duarte CA. Cirurgia Periodontal: Pré-protética, Estética e Peri-implantar. 3 ed. São Paulo: Livraria Santos Editora Ltda; 2009. 
12. Edwab RR. Choosing suture materials and needles. Dent Econ 1995 Ago; 85(8): 78-79.

13. Fedi PF, Rosenfeld WJ. Excisional new attachment procedure. J Mo Dent Assoc 1977 Dez; 57(10): 22-24.

14. Fleming J, Fouad AF, Walton RE, Lainson P. Combining endodontic, periodontic and restorative treatments. J Am Dent Assoc. 1991 Jan; 122(1): 102.

15. Gargiulo AW, Wentz FM, Orban B. Dimensions and relations of the dentogingival junction in humans. J Periodontol 1961; 32(3): 261-267.

16. Genco RJ, Cohen DW, Goldman HM. Periodontia Cotemporânea. 2 ed. São Paulo: Santos; 1997.

17. Goldman HM. Gingivectomy: Indications, Contraindications, and Method. Am J Orthod Or Sur 1946. 32(5): A323A326.

18. Gonçalves EAN, Feller C. Atualização na clínica odontológica: a prática da clínica geral. São Paulo: Artes Médicas; 1998.

19. Grossi STL, Quadros OF, Brandão GS, Ebling H. Resposta dos tecidos moles ao material de sutura. Rev Fac Odont 1971/1972; 13-14: 15-22.

20. Herrero F, Scott JB, Maropis PS, Yukna RA. Clinical Comparison of Desired Versus Actual Amount of Surgical Crown Lengthening. J Periodontol 1995. 66(7): 568-71. 
21. Ingber JS, Rose LF, Coslet JG. The "biologic width" - a concept in periodontics and restorative dentistry. Alph Om 1977 Dez; 70(3): 62-5.

22. Innes, PB. An Electron Microscopic Study of the Regeneration of Gingival Epithelium Following Gingivectomy in the Dog. J Periodontol 1970; 5: 196-204.

23. Januário AL, Barriviera M, Duarte WR. Soft tissue conebeam computed tomography: a novel method for the measurement of gingival tissue and the dimensions of the dentogingival unit. J Esthet Restor Dent 2008; 20: 366374.

24. Joly JC, De Carvalho PFM, Da Silva RC. Reconstrução Tecidual Estética - Procedimentos Plásticos e Regenerativos Periodontais e Peri-Implantares. São Pauo: Artes Médicas; 2009.

25. Kalkwarf KL. Proceedings of the world workshop in clinical periodontics. Chicago: AAP; 1989.

26. Kina JR, Dos Santos PH, Kina EFU, Suzuki TYU, Dos Santos PL. Periodontal and prosthetic biologic considerations to restore biological width in posterior teeth. J Craniofac Surg 2011; 22: 1913-1916.

27. Kois JC, Vakay RT. Clinical Techniques in Prosthodontics : Relationship of the Periodontium to Impression Procedures. Califórnia: Chairside Magaz; 2000: 684-692.

28. Koshak HH. Dental Suturing Materials and Techniques. Glob J Otolaryng 2017; 12(2): 1-11. 
29. Lindhe J, Lang NP, Karring T. Tratado de Periodontia Clínica e Implantologia Oral. 5 ed. Rio de Janeiro: Guanabara Koogan Ltda; 2011.

30. Löe H, Theilade E, Jensen SB. Experimental Gingivitis in Man. J Periontol 1965. 36(3): 177-87.

31. Miller WD. The Micro-Organisms of the Human Mouth. Independ Practit 1888; 9: 281-284.

32. Nabers CL. Repositioning the Attached Gingiva. J Periodontol 1954; 25: 38-39.

33. Nevins M, Skurow HM. The intracrevicular restorative margin, the biologic width, and the maintenance of the gingival margin. Int J Periodont Restor Dent 1984. 4: 3049.

34. Ochsenbein C. Newer Concepts of Mucogingival Surgery. J Dent Res 1960; 12(2): 237-238.

35. Page RC, Kornman KS. The Pathogenesis of Human Periodontitis: An Introduction. Periodontol 20001997. 14(1): 9-11.

36. Passanezi E, Sant'Ana ACP, Rezende MLR, Greghi SL, Janson WA. Distâncias Biológicas Periodontais: princípios para a reconstrução periodontal, estética e protética. São Paulo: Artes Médicas; 2011.

37. Petersilka GJ, Ehmke B, Flemmig TF. Antimicrobial Effects of Mechanical Debridement. Periodontol 2000 2002. 28: 56-71. 
38. Pontoriero R, Carnevale G. Surgical crown lengthening: a 12-month clinical wound healing study. J Periodontol Jul 2001; 72 (7): 841-848.

39. Ramfjord SP, Engler WO, Hiniker JJ. 1966. A Radioautographic Study of Healing Following Simple Gingivectomy. II. The Connective Tissue. J Periodontol 1966; 37(3): 179-89.

40. Ramfjord S, Ash MM. Periodontology and periodontics. Filadélfia: Saunders; 1979.

41. Rissato M, Trentin MS. Aumento de Coroa Clínica Para Restabelecimento Das Distâncias Biológicas Com Finalidade Restauradora - Revisão Da Literatura. RFO 2012 17(2): 234-39.

42. Robinson RE. The Distal Wedge Operation. Periodont 1966 Set/Out; 4(5): 256-264.

43. Saba-Chujfi. Cirurgias Plásticas Periodontais e Periimplantares: Simplificado das Propostas Técnicas. São Paulo: Santos; 2007.

44. Sameera GN, Harikumar K. Periodontal flap procedures. Ker Dent J 2011 Mar; 34(1): 174-179.

45. Schluger S, Yuodelis R, Page RC, Johnson RH. Periodontal diseases. Filadélfia: Lea \& Febiger; 1977.

46. Schmidt JC, Sahrmann P, Weiger R, Schmidlin PR, Walter C. Biologic width dimensions - a systematic review. J Clin Periodontol 2013; 40: 493-504. 
47. Staffileno H, Wentz F, Orban B. Histologic Study of Healing of Split Thickness Flap Surgery in Dogs. J Periodontol 1962; 33(1): 56-69.

48. Stanton G, Levy M, Stahl SS. Collagen Restoration in Healing Human Gingiva. J Dent Res 1969; 48(1): 27-31.

49. Stern IB, Everett FG, Robicsek K. S. Robicsek - A Pioneer in the Surgical Treatment of Periodontal Disease. J Periodontol 1965. 36: 265-68.

50. Ueti M, Matson E. Preparos dentários para prótese fixa. 1 ed. São Paulo: Panamed editorial; 1984.

51. Wagenberg BD, Eskow RN, Langer B. Exposing adequate tooth structure for restorative dentistry. Int $\mathrm{J}$ Periodontics Restorative Dent 1989; 9:322-331.

52. Watanabe Y, Suzuki S. Experimental Study on Capillary Vascularization in the Periodontal Tissue Following Gingivectomy and Flap Operation. J Dent Res 1963; 42: 758.

53. Yukna RA. A clinical and Histologic Study of Healing following the Excisional New Attachment Procedure in Rhesus Monkeys. J Periodontol 1976 Dez; 47(12): 701709 .

\section{ANEXOS}

\section{NORMAS DA REVISTA}

Os artigos para a publicação na REVISTA PERIODONTIA da 
SOBRAPE deverão ser inéditos e redigidos em português, inglês ou espanhol. Artigos originais de pesquisa terão prioridade para apreciação, mas, artigos de revisão e relatos de casos ou técnicas, de interesse na Periodontia, também poderão ser incluídos. A REVISTA PERIODONTIA reserva todos os direitos autorais do trabalho publicado. As informações contidas nos originais e publicadas na revista são de inteira responsabilidade do(s) autor(es), não refletindo necessariamente, a opinião do Corpo Editorial da revista ou a posição da SOBRAPE.

\section{Envio do Material}

Os arquivos abaixo indicados deverão ser submetidos para a Revista Periodontia pelo site www.sobrape.org.br.

- Artigo (Seguir o item "Apresentação do material") Declaração de conflito de interesses (Disponível no site Formulários) - Lista de conferência pré-submissão (Disponível no site - Formulários)

\section{Apresentação do material}

Os artigos deverão ser digitados em Word para Windows, com fonte Arial, tamanho 12, justificado, em folhas de papel A4 numeradas consecutivamente. Deve ser usado espaço duplo com margem de 2,5 centímetros de todos os lados. As laudas deverão ter em média 1.600 toques (26 linhas de toques), perfazendo no máximo 20 páginas (excluindo gráficos, figuras e tabelas).

\section{Seleção de artigos}

A seleção dos artigos enviados à REVISTA PERIODONTIA será realizada pelo Conselho Editorial, que dispõe de autoridade para decidir sobre sua aceitação. No processo de revisão e aprovação, que será realizado em pares, serão avaliados: originalidade, relevância, metodologia e adequação às normas de publicação.

\section{Considerações Éticas}

Estudos que envolvam seres humanos deverão estar de acordo com a RESOLUÇÃO 196/96 do Conselho Nacional de Saúde, e terem sido aprovados pela Comissão de Ética da Unidade 
/Instituição em que foram realizados. As mesmas considerações são feitas para estudos em animais. $O$ número de aprovação do comitê deverá estar presente no artigo.

\section{Estudos clínicos}

A Revista Periodontia estimula que os pesquisadores responsáveis por estudos clínicos façam os registros dos mesmos (www.clinicaltrials.gov).

Relatos de estudos clínicos randomizados devem contemplar os critérios disponíveis em:

http://www.consort-statement.org/

\section{Estrutura do artigo}

O trabalho deverá ser numerado (canto inferior direito) e dividido conforme os itens abaixo:

\section{Primeira página (página 1):}

- Página de título (Português e Inglês - para artigos redigidos em português; Espanhol e Inglês - para artigos redigidos em espanhol; Inglês - para artigos redigidos em inglês): deverá conter o título do artigo em negrito, o nome dos autores numerados de acordo com a filiação (instituição de origem, cidade, país), a principal titulação dos autores de forma resumida (sem nota de rodapé) e endereço do autor correspondente (contendo o endereço eletrônico - e-mail). As demais páginas devem ser na forma de texto contínuo.

Exemplo: Associação do PDGF e IGF na Regeneração Periodontal - Revisão de Literatura Fernando Hayashi ${ }^{1}$, Fernando Peixoto ${ }^{1}$, Chistiane Watanabe Yorioka ${ }^{1}$, Francisco Emílio Pustiglioni ${ }^{21}$ Mestrandos em Periodontia da FOUSP ${ }^{2}$ Professor titular de Periodontia da FOUSP

\section{Segunda página (página 2):}

- Resumo: deve fornecer uma visão concisa e objetiva do trabalho, incluindo objetivos, material e métodos, resultados e as conclusões. Deve conter no máximo 250 palavras (incluindo 
pontos, vírgulas etc). - Palavras-chave: são palavras ou expressões que identificam o conteúdo do texto. Para sua escolha, deverá ser consultada a lista "Descritores em Ciências de Saúde - DECS", da BIREME. Número de palavras-chave: máximo 6.

OBS: Para artigos redigidos em língua estrangeira, Espanhol ou Inglês, o item Resumo não configura item obrigatório.

\section{Terceira página (página 3):}

- Abstract e Keywords: cópia precisa e adequada do resumo e palavras-chave em Inglês. Deverá ser consultada a lista "Medical subject headings". Disponível em www.nlm.nih.gov/mesh/MBrowser.html. Número de Keywords: máximo 6.

- Sugere-se para autores não-nativos que procurem assistência com a sua escrita utilizando instituições especializadas como American Journal Experts (http://www.journalexperts.com)

\section{Quarta e demais páginas (página 4 e demais):}

- Introdução: é o sumário dos objetivos do estudo, de forma concisa, citando as referências mais pertinentes. Também deve apresentar as hipóteses em estudo e a justificativa do trabalho. Material e Métodos: devem ser apresentados com suficientes detalhes que permitam confirmação das observações encontradas, indicando os testes estatísticos utilizados.

- Resultados: as informações importantes do trabalho devem ser enfatizadas e apresentadas em seqüência lógica no texto, nas figuras e tabelas, citando os testes estatísticos. As tabelas e figuras devem ser numeradas (algarismo arábico) e citadas durante a descrição do texto. Cada tabela deve conter sua respectiva legenda, citada acima, em espaço duplo, em página separada, no final do artigo depois das referências. As figuras também devem estar localizadas em páginas separadas, no final do texto, porém, as legendas devem estar localizadas a baixo.

- Discussão: os resultados devem ser comparados com outros trabalhos descritos na literatura, onde também podem ser feitas 
as considerações finais do trabalho.

- Conclusão: deve responder objetivamente aos questionamentos propostos. - Agradecimentos (quando houver): a laboratórios, empresas e colegas participantes.

- Referências Bibliográficas: Essa seção será elaborada de acordo com as Normas Vancouver (disponíveis em: www.icmje.org), devendo ser numeradas seqüencialmente conforme aparição no texto. E, as abreviações das revistas devem estar em conformidade com o Index Medicus/ MEDLINE. Todos os autores da obra devem ser mencionados. Exemplos Normas Vancouver:

\section{Artigo de Revista:}

1. Lima RC, Escobar M, Wanderley Neto J, Torres LD, Elias DO, Mendonça JT et al. Revascularização do miocárdio sem circulação extracorpórea: resultados imediatos. Rev Bras Cir Cardiovasc 1993; 8: 171-176.

\section{Instituição como Autor:}

1. The Cardiac Society of Australia and New Zealand. Clinical exercise stress testing. Safety and performance guidelines. Med J Aust 1996; 116:41-42. Sem indicação de autoria: 1. Cancer in South Africa. [editorial]. S Af Med J 1994; 84-85.

\section{Capítulo de Livro:}

1. Mylek WY. Endothelium and its properties. In: Clark BL Jr, editor. New frontiers in surgery. New York: McGraw-Hill; 1998. p.55-64. Livro: 1. Nunes EJ, Gomes SC. Cirurgia das cardiopatias congênitas. 2a ed. São Paulo: Sarvier; 1961. p.701.

\section{Tese:}

1. Brasil LA. Uso da metilprednisolona como inibidor da resposta inflamatória sistêmica induzida pela circulação extracorpórea [Tese de doutorado]. São Paulo: Universidade Federal de São Paulo, Escola Paulista de Medicina, 1999. 122p. Eventos:

1. Silva JH. Preparo intestinal transoperatório. In: $45^{\circ}$ Congresso Brasileiro de Atualização em Coloproctologia; 1995; São Paulo. Anais. São Paulo: Sociedade Brasileira de Coloproctologia; 1995. 
p.27-9. 1. Minna JD. Recent advances for potential clinical importance in the biology of lung cancer. In: Annual Meeting of the American Medical Association for Cancer Research; 1984 Sep 6- 10. Proceedings. Toronto: AMA; 1984;25:293-4.

Material eletrônico: Artigo de revista: 1. Morse SS. Factors in the emergence of infectious diseases. Emerg Infect Dis [serial online] 1995 Jan-Mar [cited 1996 Jun 5]; 1(1):[24 screens]. Disponível em:

URL:

http://www.cdc.gov/ncidod/EID/eid.htm Livros: 1. Tichenor WS. Sinusitis: treatment plan that works for asthma and allergies too [monograph online]. New York: Health On the Net Foundation; 1996. [cited 1999 May 27]. Disponível em : URL: http://www.sinuses.com Capítulo de livro:

1. Tichenor WS. Persistent sinusitis after surgery. In: Tichenor WS. Sinusitis: treatment plan [monograph online]. New York: Health On the Net Foundation; 1996. [cited 1999 May 27]. Disponível em: URL: http://www.sinuses.com/postsurg.htm

\section{Tese:}

1. Lourenço LG. Relação entre a contagem de microdensidade vasal tumoral e o prognóstico do adenocarcinoma gástrico operado [tese online]. São Paulo: Universidade Federal de São Paulo; 1999. [citado 1999 Jun 10]. Disponível em: URL:http://www.epm.br/cirurgia/gastro/laercio

\section{Eventos:}

1. Barata RB. Epidemiologia no século XXI: perspectivas para o Brasil. In: $4^{\circ}$ Congresso Brasileiro de Epidemiologia [online].; 1998 Ago 1-5; Rio de Janeiro. Anais eletrônicos. Rio de Janeiro: ABRASCO; 1998. [citado 1999 Jan 17]. Disponível em: URL: http://www.abrasco.com.br/epirio98 Informações adicionais podem ser obtidas no seguinte endereço eletrônico:

http://www.nlm.nih.gov/bsd/uniform_requirements.html

- Citações no texto: Ao longo do texto, deve ser empregado o sistema autor-data. Segundo as normas Vancouver, apenas a 
primeira letra do sobrenome do autor é grafada em maiúscula, sendo o ano da publicação apresentado entre parênteses. Trabalhos com até dois autores, tem ambos os sobrenomes mencionados no texto, separados por " $\&$ ". Trabalhos com três ou mais autores, terão ao longo do texto mencionado apenas o primeiro seguido da expressão "et al".

Se um determinado conceito for suportado por vários estudos, para a citação desses, deverá ser empregada a ordem cronológica das publicações. Nesse caso, o ano de publicação é separado do autor por virgule e as diferentes publicações separadas por ponto e vírgula.

- Declaração de conflitos de interesse e fomento: esse é um item obrigatório que deve ser conciso indicando: a) se houve apoio financeiro de qualquer natureza devendo-se nesse caso mencionar nominalmente a agência de fomento e b) se há qualquer tipo de conflito de interesse relacionado à pesquisa em questão. Em casos negativos sugere-se o uso da frase

Os autores declaram a inexistência de conflito de interesse e apoio financeiro relacionados ao presente artigo.

\section{- Figuras e Tabelas}

As tabelas e figuras deverão ser apresentadas em folhas separadas após a secção: Referências Bibliográficas (uma tabela/figura por folha com a sua respectiva legenda). Figuras em formato digital (arquivo JPG ou TIFF): Resolução de 300 DPIs. As imagens serão publicadas em preto e branco. Caso haja interesse dos autores há possibilidade de impressão colorida das imagens, havendo custo adicional de responsabilidade dos autores. 